\title{
¿Weakening of Cold Halocline Layer Exposes Sea Ice to Oceanic Heat in the Eastern Arctic Ocean
}

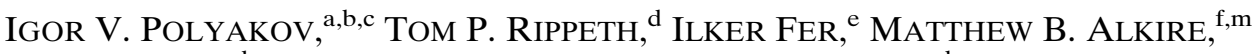 \\ TILl M. BAUMANN, ${ }^{\mathrm{a}, \mathrm{b}, \mathrm{c}}$ EDDY C. CARMACK, ${ }^{\mathrm{g}}$ RANDI INGVALDSEN, ${ }^{\mathrm{h}}$ VLADIMIR V. IVANOV, ${ }^{\mathrm{i}, \mathrm{j}}$ \\ MARKuS JANOUT, ${ }^{\mathrm{k}}$ Sigrid Lind, ${ }^{\mathrm{h}}$ LAURIE PADMAn, ${ }^{\mathrm{l}}$ ANDREY V. PNYUSHKOV, ${ }^{\mathrm{a}}$ \\ AND ROBERT REMBER ${ }^{\mathrm{a}}$

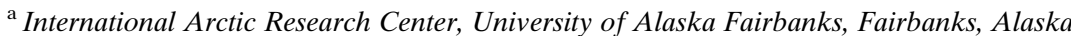 \\ ${ }^{\mathrm{b}}$ College of Natural Science and Mathematics, University of Alaska Fairbanks, Fairbanks, Alaska \\ ${ }^{\mathrm{c}}$ Finnish Meteorological Institute, Helsinki, Finland \\ ${ }^{\mathrm{d}}$ School of Ocean Sciences, Bangor University, Menai Bridge, United Kingdom \\ ${ }^{\mathrm{e}}$ Geophysical Institute, University of Bergen and Bjerknes Centre for Climate Research, Bergen, Norway \\ ${ }^{\mathrm{f}}$ Polar Science Center, Applied Physics Lab, University of Washington, Seattle, Washington \\ ${ }^{\mathrm{g}}$ Institute of Ocean Sciences, Fisheries and Oceans Canada, Sidney, British Columbia, Canada \\ ${ }^{\mathrm{h}}$ Institute of Marine Research, Bergen, Norway \\ ${ }^{\mathrm{i}}$ Geography Department, Lomonosov Moscow State University, Moscow, Russia \\ ${ }^{\mathrm{j}}$ Arctic and Antarctic Research Institute, Ocean-air interaction department, St.Petersburg, Russia \\ ${ }^{\mathrm{k}}$ Alfred Wegener Institute, Helmholtz Centre for Polar and Marine Research, Bremerhaven, Germany \\ ${ }^{1}$ Earth and Space Research, Corvallis, Oregon
}

(Manuscript received 1 January 2020, in final form 16 June 2020)

\begin{abstract}
A 15-yr duration record of mooring observations from the eastern $\left(>70^{\circ} \mathrm{E}\right)$ Eurasian Basin (EB) of the Arctic Ocean is used to show and quantify the recently increased oceanic heat flux from intermediate-depth $(\sim 150-900 \mathrm{~m})$ warm Atlantic Water (AW) to the surface mixed layer and sea ice. The upward release of AW heat is regulated by the stability of the overlying halocline, which we show has weakened substantially in recent years. Shoaling of the AW has also contributed, with observations in winter 2017-18 showing AW at only $80 \mathrm{~m}$ depth, just below the wintertime surface mixed layer, the shallowest in our mooring records. The weakening of the halocline for several months at this time implies that AW heat was linked to winter convection associated with brine rejection during sea ice formation. This resulted in a substantial increase of upward oceanic heat flux during the winter season, from an average of $3-4 \mathrm{~W} \mathrm{~m}^{-2}$ in 2007-08 to $>10 \mathrm{~W} \mathrm{~m}^{-2}$ in 2016-18. This seasonal AW heat loss in the eastern EB is equivalent to a more than a twofold reduction of winter ice growth. These changes imply a positive feedback as reduced sea ice cover permits increased mixing, augmenting the summer-dominated ice-albedo feedback.
\end{abstract}

\section{Introduction}

In recent decades there has been a dramatic decline in seasonal sea ice extent in the Arctic Ocean, with a more recent year-around decline in sea ice extent, area, and

Denotes content that is immediately available upon publication as open access.

${ }^{\mathrm{m}}$ Current affiliation: School of Oceanography, University of Washington, Seattle, Washington.

Corresponding author: Igor Polyakov, ivpolyakov@alaska.edu volume (Kwok 2018; Stroeve and Notz 2018). This change has shifted the local radiative balance resulting in a positive ice-albedo feedback mechanism as increasing lead fraction and surface melt pond areas in decaying Arctic sea ice facilitate enhanced upper-ocean solar heating and more rapid melting of ice floes (e.g., Perovich et al. 2008; Toole et al. 2010). Moreover, it was hypothesized that the declining sea ice has larger-scale hemispheric impacts on the North Atlantic Oscillation and, in consequence, midlatitude weather patterns (e.g., Francis et al. 2017; García-Serrano et al. 2015; Kolstad and Screen 2019).

Heat associated with oceanic currents originating from lower latitudes provides an important, and yearround, source of heat to the Arctic Ocean (e.g., Carmack 

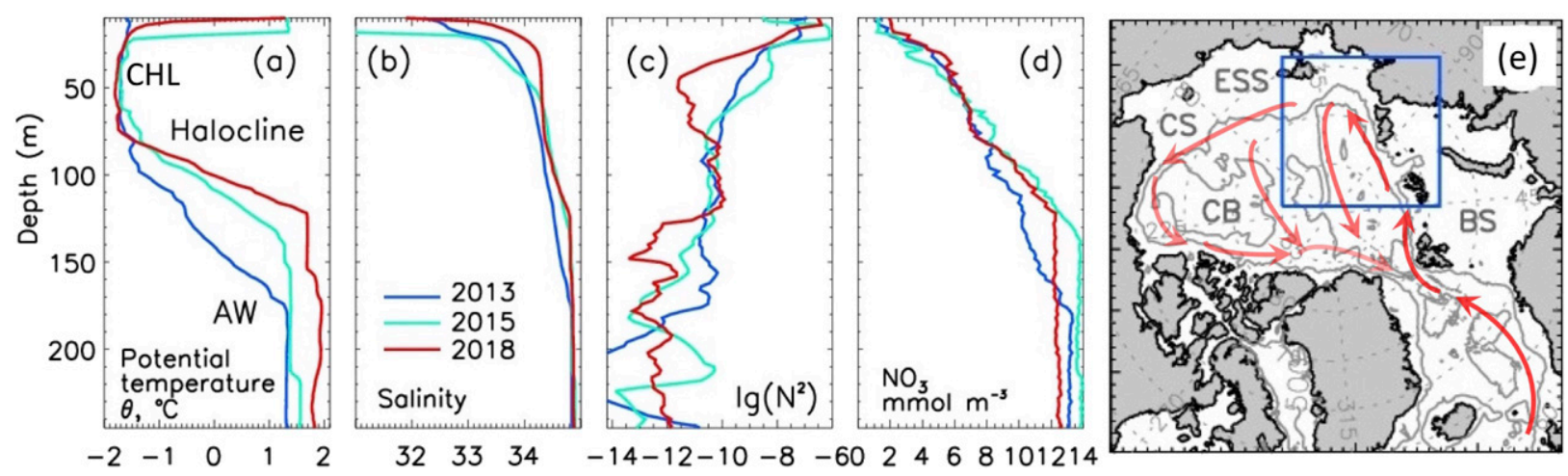

FIG. 1. Vertical profiles of (a) potential temperature $\theta$, (b) salinity $S$, (c) the logarithm of squared Brunt-Väisälä frequency $N^{2}$ (s ${ }^{-2}$; a measure of water column stability; 5-point smoothing is applied), and (d) nutrients represented by $\mathrm{NO}_{3}$ at the $\mathrm{M}_{4}$ mooring site made on 27 Aug 2013, 20 Sep 2015, and 2 Sep 2018. (e) Circulation of the intermediate Atlantic Water (AW) in the Arctic Ocean is shown schematically by red arrows. The blue box indicates the area of the Arctic Ocean with mooring positions shown in Fig. 2. The Canada Basin (CB), Chukchi Sea (CS), East Siberian Sea (ESS), and Barents Sea (BS) are indicated. The location of the halocline (region of strong vertical salinity gradient) including the cold halocline layer (CHL; where temperature is near the freezing point) is indicated in (a).

et al. 2015). The dominant external source of oceanic heat is the warm (temperature $>0^{\circ} \mathrm{C}$ ) and salty water of Atlantic origin [Atlantic Water (AW)], which is distributed throughout the deep basins at intermediate depths ( 150-900 m; Fig. 1) and holds sufficient heat to melt the Arctic sea ice 3-4 times over (Carmack et al. $2015)$. Across much of the eastern $\left(>70^{\circ} \mathrm{E}\right)$ Eurasian Basin (EB) this heat is isolated from the surface, and hence the sea ice, by large vertical density gradients associated with the Arctic halocline (60-150 m; Fig. 1). The presence of the halocline impedes the transport of AW heat upward toward the surface across much of the Arctic Ocean (e.g., Fer 2009). The exception to this is the western $\left(<70^{\circ} \mathrm{E}\right)$ Nansen Basin where substantial turbulent mixing linked to the tides (Fer et al. 2010; Padman and Dillon 1991; Rippeth et al. 2015; Renner et al. 2018) and wind events (e.g., Provost et al. 2017; Graham et al. 2019) supports heat fluxes in excess of $50 \mathrm{~W} \mathrm{~m}^{-2}$.

Inflowing AW is warming (Barton et al. 2018) driving a regime shift in sea ice cover over the past decade in the Barents Sea (Onarheim et al. 2018). There is also a growing body of evidence that the characteristics of the Arctic halocline are changing; for example, the halocline has weakened in the eastern EB since the 1970s (Steele and Boyd 1998; Polyakov et al. 2010). These changes have accelerated over the past decade (Polyakov et al. 2020a) with continuous time series from moored instruments capturing the significant weakening of the cold halocline layer (the upper part of the halocline with temperatures near freezing and negligible vertical temperature gradient) and shoaling of the AW in 2013-15 (Polyakov et al. 2017).

The combination of weaker stratification and shoaling of the AW in the EB, coupled with the loss of sea ice, has allowed progressively deeper winter ventilation in the eastern EB in recent years (Polyakov et al. 2017). This process further enhances the annually averaged upward AW heat fluxes. The shift in sea ice state and upper ocean stratification to conditions previously unique to the western Nansen Basin has been termed "Atlantification" (Polyakov et al. 2017) and represents a transition toward a new Arctic climate state, in which the geographical influence of the AW heat on sea ice volume is spreading eastward.

Since the increased oceanic heat fluxes associated with Atlantification drive sea ice melt, and reduced sea ice increases oceanic heat fluxes through increased convective entrainment in winter, this process represents a positive ice-ocean-heat feedback mechanism. This mechanism is analogous and complementary to the icealbedo feedback, in which atmospheric warming leads to a reduction of ice and snow coverage and decreasing albedo, resulting in further snow and sea ice retreat (Manabe and Stouffer 1980).

The strength of the ice-ocean-heat feedback is determined by the vertical flux of AW heat across the halocline into the surface-forced seasonal convective layer. Polyakov et al. (2017) estimated seasonal changes of heat content $Q$ in the eastern EB halocline (65$130 \mathrm{~m}$ ) and an equivalent divergent heat flux (the difference of fluxes at two depth levels for which a $1 \mathrm{D}$ equation of heat balance for a unit-area water column is integrated) of $\delta F_{h} \sim 12 \mathrm{~W} \mathrm{~m}^{-2}$ over this depth range for winter 2013/14, and $\sim 8 \mathrm{~W} \mathrm{~m}^{-2}$ for winter 2014/15. They argued that these inferred values of $\delta F_{h}$ exceeded previous regional estimates (e.g., Lenn et al. 2009; Polyakov et al. 2013) by a factor of $2-4$ and potentially account for an additional loss of up to $18-40 \mathrm{~cm}$ of sea ice over this 
period of time associated with the increase in upward AW heat transport. In consequence the impact of the oceanic heat flux on sea ice formation in 2013-15 was comparable to that of the atmospheric thermodynamic forcing (Polyakov et al. 2017).

The aim of this paper is to quantify the changes in the upper ocean heat content, and the consequent release of heat from the AW up into the halocline and to the surface mixed layer in the key eastern Eurasian Basin of the Arctic Ocean. We improve on the Polyakov et al. (2017) study by including new data collected over the period 2015-18 to quantify changes in the upper ocean heat content, and the consequent release of heat from the AW up into the halocline and to the surface mixed layer in the EB. We then compare these regional estimates with earlier estimates.

\section{Data}

Our analyses utilize observations of ocean temperature, salinity, and currents from moorings deployed in the eastern EB (Fig. 2, Table 1). Observations at the $\mathrm{M}_{4}$ mooring site began in August 2002, with several collocated moorings deployed and recovered annually prior to 2009, and longer duration of deployments since 2013 (Table 1).

Moorings deployed in summer 2013 and recovered in summer 2015 provided 2-yr-long records for most instruments except for the $\mathrm{M} 1_{5}$ upper ocean acoustic Doppler current profiler (ADCP), which worked for 10 months only. Mooring M3 located off the Novisibirskiye Islands was deployed at water depth of $1350 \mathrm{~m}$. Six moorings $\left(\mathrm{M} 1_{1}-\mathrm{M} 1_{6}\right)$ formed a $\sim 350-\mathrm{km}$ cross-slope section spanning from the 250 to $3400 \mathrm{~m}$ isobaths along $126^{\circ} \mathrm{E}$. A topographically steered boundary current flows along slope across this section (Pnyushkov et al. 2015, 2018a). Averaged over 2013-15, the maximum current speed of $\sim 11 \mathrm{~cm} \mathrm{~s}^{-1}$ was found at the shallowest mooring $\mathrm{M} 1$ ( on the $250 \mathrm{~m}$ isobath), with only $\sim 0.5 \mathrm{~cm} \mathrm{~s}^{-1}$ in the deep basin at moorings $\mathrm{M} 1_{5}$ and $\mathrm{M}_{6}$. The $\mathrm{AW}$ core defined by the maximum water temperature is typically located at a depth of $\sim 250 \mathrm{~m}$ at the $\mathrm{M} 1_{5}$ mooring site.

Deployment of moorings in 2015-18 repeated the mooring distribution used for 2013-15 except that the M1 6 mooring was not redeployed (Table 1). Almost all mooring instruments provided full 3-yr-long records; the $\mathrm{M}_{3}$ McLane Moored Profiler (MMP) stopped recording after two years. In addition, a short-term mooring, $\mathrm{M} 1_{4 \text {-short }}$, was deployed for 18 days only (2-20 September 2018) close to the $\mathrm{M}_{4}$ climatologic mooring site (Table 1 ). The short-term mooring was designed to provide current and CTD data with the most rapid possible sampling rate in the upper $200 \mathrm{~m}$.

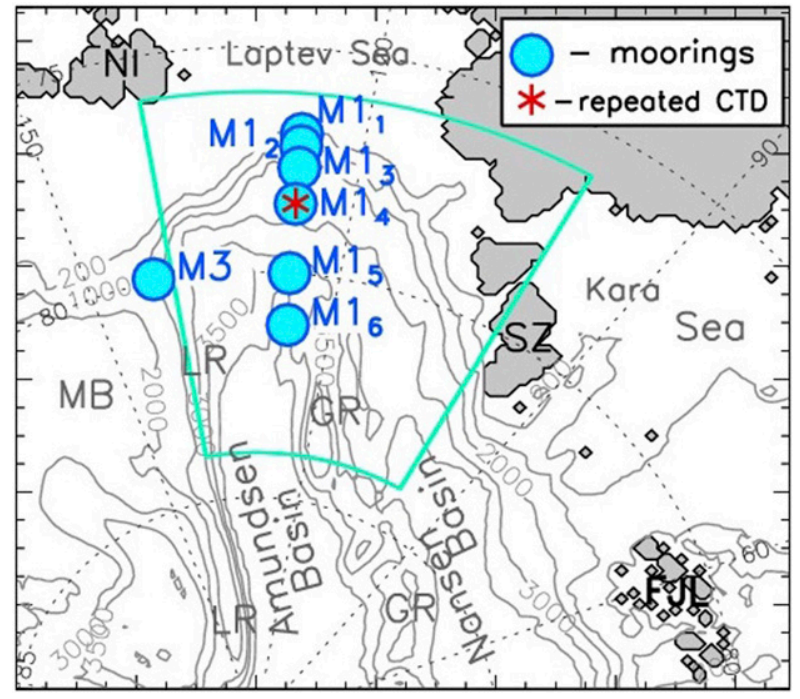

FIG. 2. Map showing the focus of the study together with the positions of moorings and location of CTD profiles made in summer 2013, 2015, and 2018 reported in this study. The Gakkel Ridge (GR) divides the Eurasian Basin (EB) into the Nansen Basin and the Amundsen Basin. The Lomonosov Ridge (LR), Novosibirskiye Islands (NI), Severnaya Zemlya (SZ), Franz Joseph Land (FJL), and Makarov Basin (MB) are indicated. Gray solid lines show depth in meters. The eastern EB region used for calculation of blue time series in Fig. 10 is identified by the green line.

\section{a. Mooring conductivity-temperature-depth data}

The MMP-based moorings at the $\mathrm{M}_{4}$ mooring location in 2002-09 collected temperature, salinity, and current velocity profiles once per day. Four 2013-15 moorings $\left(\mathrm{M}_{2}, \mathrm{M} 1_{3}, \mathrm{M} 1_{5}\right.$, and $\left.\mathrm{M} 1_{6}\right)$ and two 2015-18 moorings ( $\mathrm{M}_{3}$ and $\mathrm{M} 1_{5}$ ) provided vertical MMP profiles with 2-day sampling interval and $\sim 0.25$-m vertical spacing. The MMPs on most moorings sampled the 50-700 m depth range; however, the $2015-18 \mathrm{M}_{5}$ mooring missed its target depth and the MMP record only reached to $\sim 170 \mathrm{~m}$ below the surface. The MMP on the M1 $1_{4 \text {-short }}$ mooring sampled about every $18 \mathrm{~min}$ and obtained 1369 profiles. The MMP temperature and conductivity calibrated measurement accuracies are $\pm 0.002^{\circ} \mathrm{C}$ and $\pm 0.002 \mathrm{mS} \mathrm{cm}^{-1}$.

The moorings $\mathrm{M} 1_{1}, \mathrm{M}_{2}, \mathrm{M}_{4}$, and $\mathrm{M} 3$ with no MMP profilers deployed in 2013-18, as well as mooring M1g, deployed about $12 \mathrm{~km}$ from mooring $\mathrm{M}_{4}$ in 2008-10 (Fig. 2, Table 1), were equipped with Seabird SBE-37 conductivity-temperature-depth (CTD) instruments and provided records of conductivity, temperature, and pressure with sampling interval of $1 \mathrm{~h}$ or shorter, with measurement accuracies for temperature and conductivity of $\pm 0.002^{\circ} \mathrm{C}$ and $\pm 0.003 \mathrm{mS} \mathrm{cm}^{-1}$, respectively.

\section{b. Mooring current data}

Most moorings used in this analysis included $300-\mathrm{kHz}$ ADCPs targeting the upper $50-60 \mathrm{~m}$ of the water 
TABLE 1. Summary of moorings used in this study (only those instruments are shown which records have been used here). For mooring locations, see Fig. 2.

\begin{tabular}{|c|c|c|c|c|c|c|}
\hline Mooring & Latitude $\left({ }^{\circ} \mathrm{N}\right)$, longitude $\left({ }^{\circ} \mathrm{E}\right)$ & Depth (m) & Instrument & Depth range $(\mathrm{m})$ & Beginning of record & End of record \\
\hline \multicolumn{7}{|c|}{ Moorings deployed in $2002-09$ and collocated with $\mathrm{M}_{4}$ mooring } \\
\hline \multirow[t]{2}{*}{ M1a } & $78,27.360$ & 2680 & MMP & $164-2598$ & 2 Sep 2002 & 1 Sep 2003 \\
\hline & $125,40.440$ & & SBE37 & 57,136 & & \\
\hline \multirow[t]{2}{*}{ M1b } & $78,26.637$ & 2686 & MMP & $104-1484$ & 8 Sep 2003 & 9 Sep 2004 \\
\hline & $125,40.194$ & & & & & \\
\hline \multirow[t]{2}{*}{ M1c } & $78,26.637$ & 2690 & $\mathrm{ADCP}$ & $5-50$ & 14 Sep 2004 & 15 Sep 2005 \\
\hline & $125,40.194$ & & MMP & $72-900$ & 15 Sep 2004 & $16 \mathrm{Jul} 2005$ \\
\hline \multirow[t]{2}{*}{ M1e } & $78,25.940$ & 2692 & $\mathrm{ADCP}$ & $5-57$ & 2 Sep 2006 & 18 Sep 2007 \\
\hline & $125,43.419$ & & MMP & $70-900$ & & 11 Nov 2006 \\
\hline \multirow[t]{2}{*}{ M1g } & 7825.735 & 2765 & $\mathrm{ADCP}$ & $20-130$ & 18 Oct 2008 & 16 Jun 2010 \\
\hline & $125,28.527$ & & SBE37 & $110,116,132,339$ & 19 Oct 2008 & 22 Sep 2011 \\
\hline \multirow{3}{*}{$\mathrm{M} 1_{1}$} & & Moo & ring sections & $\mathrm{M} 1_{1}-\mathrm{M} 1_{6}, 2013-15$ & & \\
\hline & $77,04.252$ & 250 & $\mathrm{ADCP}$ & $20-250$ & 26 Aug 2013 & 10 Sep 2015 \\
\hline & $125,48.288$ & & & & & \\
\hline \multirow[t]{2}{*}{$\mathrm{M} 1_{2}$} & $77,10.376$ & 787 & $\mathrm{ADCP}$ & $5-63$ & 27 Oct 2013 & 1 Sep 2015 \\
\hline & $125,47.516$ & & MMP & $70-754$ & 26 Aug 2013 & 31 Aug 2015 \\
\hline \multirow[t]{2}{*}{$\mathrm{M}_{3}$} & $77,39.286$ & 1849 & $\mathrm{ADCP}$ & $5-56$ & 6 Sep 2013 & 2 Sep 2015 \\
\hline & $125,48.401$ & & MMP & $64-750$ & 7 Sep 2013 & 3 Sep 2015 \\
\hline \multirow{3}{*}{$\mathrm{M}_{4}$} & $78,27.543$ & 2721 & $\mathrm{ADCP}$ & $5-55$ & & \\
\hline & $125,53.758$ & & $\mathrm{ADCP}$ & $193-463$ & 5 Sep 2013 & 19 Sep 2015 \\
\hline & & & SBE37 & $62,129,214,265,617$ & & \\
\hline \multirow{2}{*}{$\mathrm{M} 1_{5}$} & $80,00.199$ & 3443 & ADCP & $23-83$ & & 16 Jun 2014 \\
\hline & $125,59.673$ & & MMP & $88-754$ & 28 Aug 2013 & 21 Aug 2015 \\
\hline \multirow[t]{2}{*}{$\mathrm{M} 1_{6}$} & $81,08.182$ & 3900 & ADCP & $5-55$ & 29 Aug 2013 & 4 Sep 2015 \\
\hline & $125,42.673$ & & MMP & $60-754$ & & 22 Aug 2015 \\
\hline \multirow{3}{*}{$\mathrm{M} 1_{1}$} & & Moo & ring section & $\mathrm{M} 1_{1}-\mathrm{M} 1_{5}, 2015-18$ & & \\
\hline & $77,04.221$ & 252 & $\mathrm{ADCP}$ & $200-232$ & 21 Sep 2015 & 3 Sep 2018 \\
\hline & $125,49.577$ & & & & & \\
\hline \multirow[t]{2}{*}{$\mathrm{M} 1_{2}$} & $77,10.373$ & 783 & $\mathrm{ADCP}$ & $5-60$ & 21 Sep 2015 & 3 Sep 2018 \\
\hline & $125,47.974$ & & SBE & $31,44,67,138,213,266,628$ & & \\
\hline \multirow[t]{2}{*}{$\mathrm{M}_{3}$} & $77,39.234$ & 1866 & $\mathrm{ADCP}$ & $5-55$ & 21 Sep 2015 & 3 Sep 2018 \\
\hline & $125,48.686$ & & MMP & $70-1056$ & 22 Sep 2015 & 15 Jun 2017 \\
\hline \multirow[t]{3}{*}{$\mathrm{M}_{4}$} & $78,28.084$ & 2700 & $\mathrm{ADCP}$ & $5-30$ & 21 Sep 2015 & \\
\hline & $125,57.679$ & & $\mathrm{ADCP}$ & $155-430$ & & 18 Sep 2018 \\
\hline & & & SBE37 & $38,107,188,240,604$ & & \\
\hline \multirow[t]{3}{*}{$\mathrm{M}_{5}$} & $79,56.194$ & 3443 & $\mathrm{ADCP}$ & $5-61$ & 21 Sep 2015 & 31 Aug 2018 \\
\hline & $126,01.228$ & & MMP & $172-806$ & 24 Sep 2015 & 29 Aug 2018 \\
\hline & & $\mathrm{M}$ & pring $\mathrm{M}_{4-\mathrm{s}}$ & (2-20 Sep 2018) & & \\
\hline \multirow[t]{2}{*}{$\mathrm{M} 1_{4 \text {-short }}$} & $78,30.833$ & 2700 & MMP & 30-194 & 2 Sep 2018 & 20 Sep 2018 \\
\hline & $125,58.924$ & & & & & \\
\hline \multirow{3}{*}{ M3e } & & & Moo & M3 & & \\
\hline & $79,56.136$ & 1335 & ADCP & $5-61$ & 31 Aug 2013 & 7 Sep 2015 \\
\hline & $142,14.887$ & & SBE & $41,45,57,64,130,270,600$ & & \\
\hline \multirow[t]{2}{*}{ M3f } & $79,56.194$ & 1357 & $\mathrm{ADCP}$ & $5-44$ & 7 Sep 2015 & 6 Sep 2018 \\
\hline & $142,15.216$ & & SBE & $30,50,133,217,268,614$ & & \\
\hline
\end{tabular}

column (Table 1). Moorings with no MMP were equipped with long-range 75-kHz ADCPs covering deeper layers (Table 1). ADCPs provided current velocities, averaged over $2 \mathrm{~m}$ (prior to 2013) or $4 \mathrm{~m}$ (after 2013) vertical cells, with 1 -h time resolution. The manufacturer's estimates for $300-\mathrm{kHz}$ ADCP accuracies are $0.5 \%$ of measured speed and $2^{\circ}$ for current direction.

Moorings equipped with MMPs provided current velocity profiles with above mentioned profiling intervals and $0.25-\mathrm{m}$ vertical resolution. The MMPs were equipped with a Falmouth Scientific Inc. (FSI) microCTD sensor in 2002-04 and a Sea-Bird Electronics (SBE) 41CP CTD sensor starting from 2004, with temperature and conductivity measurement accuracies of about $\pm 0.002^{\circ} \mathrm{C}$ and $\pm 0.0003 \mathrm{~S} \mathrm{~m}^{-1}$, respectively. Prior to 2013, each MMP carried an FSI Acoustic Current Meter (ACM); after 2013, the ACMs were substituted with the FSI ACM-PLUS-MP (http://www.falmouth.com/ product-information.html). The velocity precision of the FSI ACM (ACM-PLUS-MP) carried on the MMP is 
reported to be $\pm 2 \%$ ( $1 \%$ ) of reading and $\pm 0.5 \mathrm{~cm} \mathrm{~s}^{-1}$ for velocity resolution. Compass accuracy is $\pm 2^{\circ}$. All MMP sensors were calibrated before their deployment and immediately after their recovery using McLane facilities.

\section{c. Shipborne CTD data}

Mooring observations were complemented by repeated hydrographic profiles collected using a Seabird SBE911plus CTD system in 2013, 2015, and 2018 at the $\mathrm{M}_{4}$ mooring site (Fig. 2). The effective vertical resolution, considering the different sensor characteristics, is about $0.25 \mathrm{~m}$. Individual temperature and conductivity measurements are accurate to $\pm 0.002^{\circ} \mathrm{C}$ and $\pm 0.0003 \mathrm{~S} \mathrm{~m}^{-1}$.

\section{Methods}

\section{a. Defining a proxy for the Richardson number}

The Richardson number ( $\mathrm{Ri}$ ) is a measure of the stability of the water column; when $\mathrm{Ri}<0.25$ the vertical shear in the flow is sufficient to generate dynamic instabilities and turbulent mixing. As such, Ri estimates provide a useful indicator for the likelihood of shear instability and mixing. The correct scale for the estimation of Ri is the Ozmidov scale [which in this case we estimate to be $O(0.1) \mathrm{m}]$. However, the vertical resolution of the $\mathrm{Ri}$ estimate is limited by the positions of instruments on the moorings, which have a vertical resolution of $20 \mathrm{~m}$. While the $20-\mathrm{m}$ Ri estimates are likely to smooth out the fine structure of individual instabilities, we argue that the smaller the large-scale $\mathrm{Ri}$ value is, the greater the likelihood of shear instability (and so turbulence and mixing). As such, the 20-m Ri provides a useful proxy for the likelihood of shear instability. Moreover, trends in the $20-\mathrm{m}$ (proxy) Ri estimate will expose trends in the likelihood of shear instability, the key interpretation here. This approach is supported by direct comparisons of dissipation and low resolution Ri estimates (e.g., Mead Silvester et al. 2014).

The mooring-based estimates of Ri (Fig. 3) are based on MMP measurements of stratification and velocity. Stratification over the $100-140 \mathrm{~m}$ layer is quantified using buoyancy frequency $N$, where $N^{2}=-\left(g / \rho_{o}\right) \partial \rho / \partial z$, where $\rho$ is the potential density of seawater, $\rho_{o}$ is the reference density $\left(1030 \mathrm{~kg} \mathrm{~m}^{-3}\right)$, and $g$ is the acceleration due to gravity. The limited depth range of 100 $140 \mathrm{~m}$ was chosen due to insufficient data coverage in early years (see Table 1 ). The Ri proxy was estimated as $\mathrm{Ri}=N^{2} /\left|\mathbf{U}_{z}\right|^{2}$, where $\left|\mathbf{U}_{z}\right|$ is the magnitude of the vertical shear of the horizontal currents; $\left|\mathbf{U}_{z}\right|$ and $N$ were calculated averaging gradients over 20 -m vertical scale for all points within the $100-140 \mathrm{~m}$ depth range.

\section{b. Defining timing and depth of seasonal upper ocean ventilation and divergent heat flux $\delta F_{h}$}

For this analysis, temperature observations at $\mathrm{M}_{2}$, $\mathrm{M} 1_{3}, \mathrm{M} 1_{4}$, and $\mathrm{M} 3$ moorings in 2013-18 were used. SBE37 data from non-MMP moorings $\mathrm{M}_{2}$ (2015-18), $\mathrm{M} 1_{3}$, $\mathrm{M}_{4}$, and $\mathrm{M} 3$ were complemented by MMP profiles from the $\mathrm{M}_{2}$ (2013-15) mooring. SBE-37 observations were linearly interpolated to match the MMP vertical resolution. We are interested in the analysis of seasonal ventilation of the halocline. Accordingly, temperature observations were filtered using wavelet transformations to keep seasonal variations only (and thus the different temporal sampling by MMP and SBE-37 did not affect our results). A standard package of wavelet programs was used based on the derivative of Gaussian (DoG) mother function. Estimates of heat content $Q$ $\left(\mathrm{J} \mathrm{m}^{-3}\right.$, with freezing point taken as a reference temperature at a given salinity) for the halocline $(65-140 \mathrm{~m})$ are shown in Fig. 4. To check that the use of SBE-37 point measurements with relatively coarse vertical resolution and continuous MMP profiles for estimates of $Q$ did not affect our results we calculated $Q$ using MMP temperature record from $\mathrm{M}_{2}$ mooring (2015-18) twice, first with original MMP resolution and again with subsampled coarser resolution matching SBE-37 depth levels (Table 1). The estimates of $Q$ integrated over the halocline depth range and averaged in time over the entire record length differed by $8 \%$.

The aim is to define the timing and amplitude of upward heat flux associated with winter ventilation. To this end, we identified timing and amplitude of the maximum $Q$ (as accumulated over the warm phase of the seasonal cycle) and the minimum of $Q$ (associated with winter ventilation) using $Q$ vertically integrated over $65-140 \mathrm{~m}$. The depth of the ventilation is defined as the deepest point where a distinct minimum of $Q$ was found. The maximum of vertically integrated $Q$ was then recalculated using the depth of ventilation.

Following Polyakov et al. (2017), we limited the boundary of the winter ventilation layer to $140 \mathrm{~m}$. For some years, the boundary of the layer was deeper than $140 \mathrm{~m}$ (as shown in Fig. 4 by the black horizontal segments located at the very bottom of the panels with $Q$ ). Therefore, our choice of the ventilation layer is conservative and estimates of divergent heat fluxes $\delta F_{h}$ derived from change of heat content $\Delta Q$ during each winter season represent the lower bound, consistent with the objectives of the study. For the upper boundary of the layer for which $Q$ is estimated, we selected the depth $65 \mathrm{~m}$, chosen because this best determines the halocline layer in which heat from the AW is stored and released (Polyakov et al. 2013, 2017). We evaluated the 

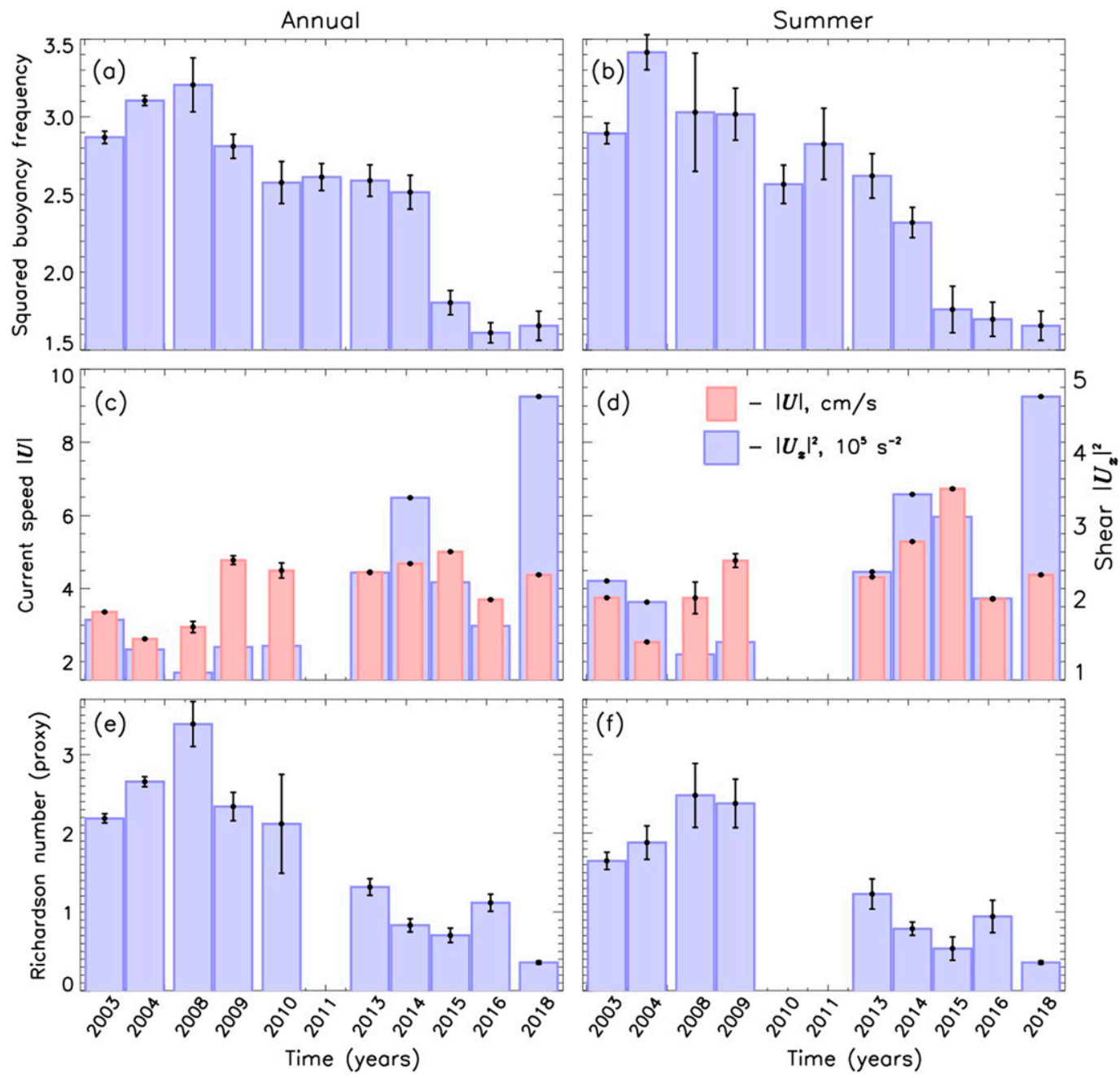

FIG. 3. Estimates of (left) annual and (right) summer mean (a),(b) squared buoyancy frequency $N^{2}\left(10^{5} \mathrm{~s}^{-2}\right)$, (c),(d) current magnitude $|\mathbf{U}|$ and squared vertical shear of horizontal currents $\left|\mathbf{U}_{z}\right|^{2}$, and (e),(f) proxy of Richardson number $\mathrm{Ri}$ for the $110-140 \mathrm{~m}$ depth range for the $\mathrm{M} 1_{4}$ mooring location. Statistical significance of means is shown at the $95 \%$ confidence level.

sensitivity of our estimates to the choice of the boundary of the ventilation layer by calculating $\delta F_{h}$ for $65-140 \mathrm{~m}$ and $65-150 \mathrm{~m}$ layers. The $10-\mathrm{m}$ increase in layer thickness increases $\delta F_{h}$ by less than $8 \%$.

Following Polyakov et al. (2013), we estimated $\delta F_{h}$ $\left(\mathrm{W} \mathrm{m}^{-2}\right)$ between two depth levels as the change, in time, of vertically integrated $Q$. This approach is based on the assumption that all change in heat content is due to vertical exchange (i.e., 1D). Note that these values are flux differences between two depth levels, and total heat fluxes may be larger than these values due to additional nondivergent heat transports; thus, our inferred estimates of divergent heat fluxes represent lower bounds for the total heat flux [for details, see Polyakov et al. (2013)].

\section{Results}

\section{a. AW warming and weakening of halocline} stratification in the eastern Eurasian Basin

Time series of the AW temperature show significant interannual variability (Fig. 5a). The AW in the eastern EB began warming in the early 2010 s, with the AW temperature in 2018 being, on average, $0.5^{\circ}-0.7^{\circ} \mathrm{C}$ higher than in 2011 (Fig. 5a). This recent warming is particularly noticeable at shallower depths, with the increase in temperature at $150 \mathrm{~m}$ exceeding $1.5^{\circ} \mathrm{C}$ between 2011 and 2018. This warming over the depth range 150-750 m between September 2013-May 2014 and September 2016-May 2017 is partially associated with shoaling of the upper halocline boundary 

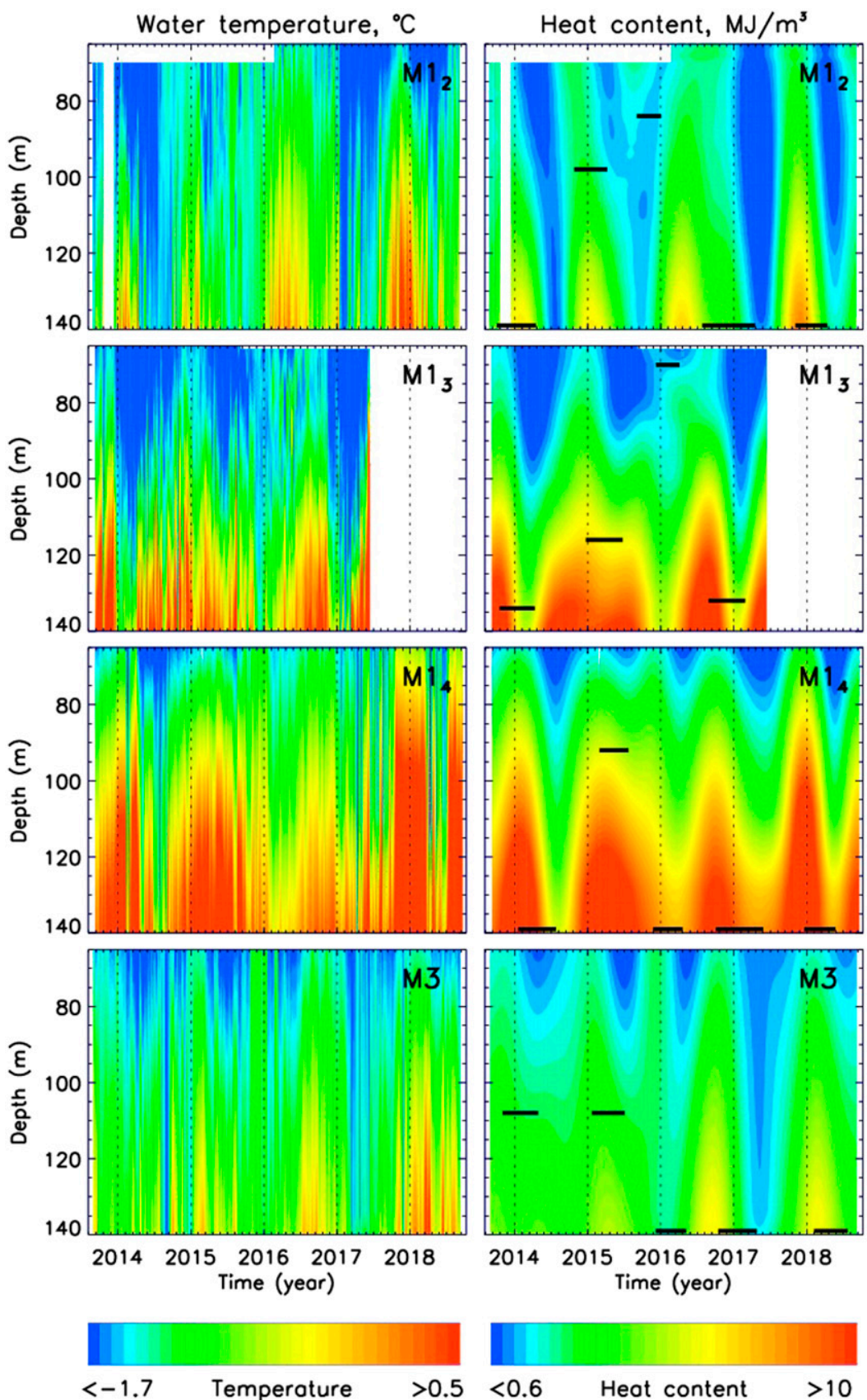
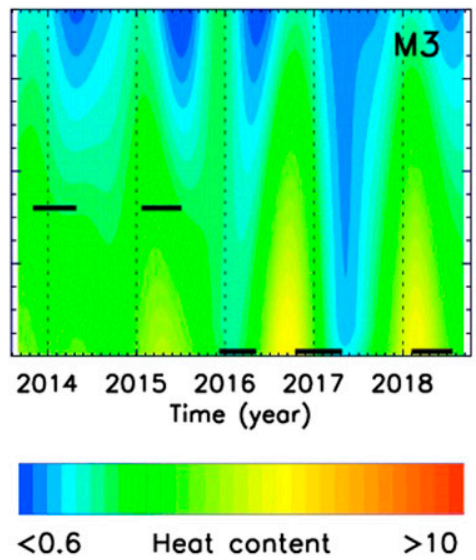
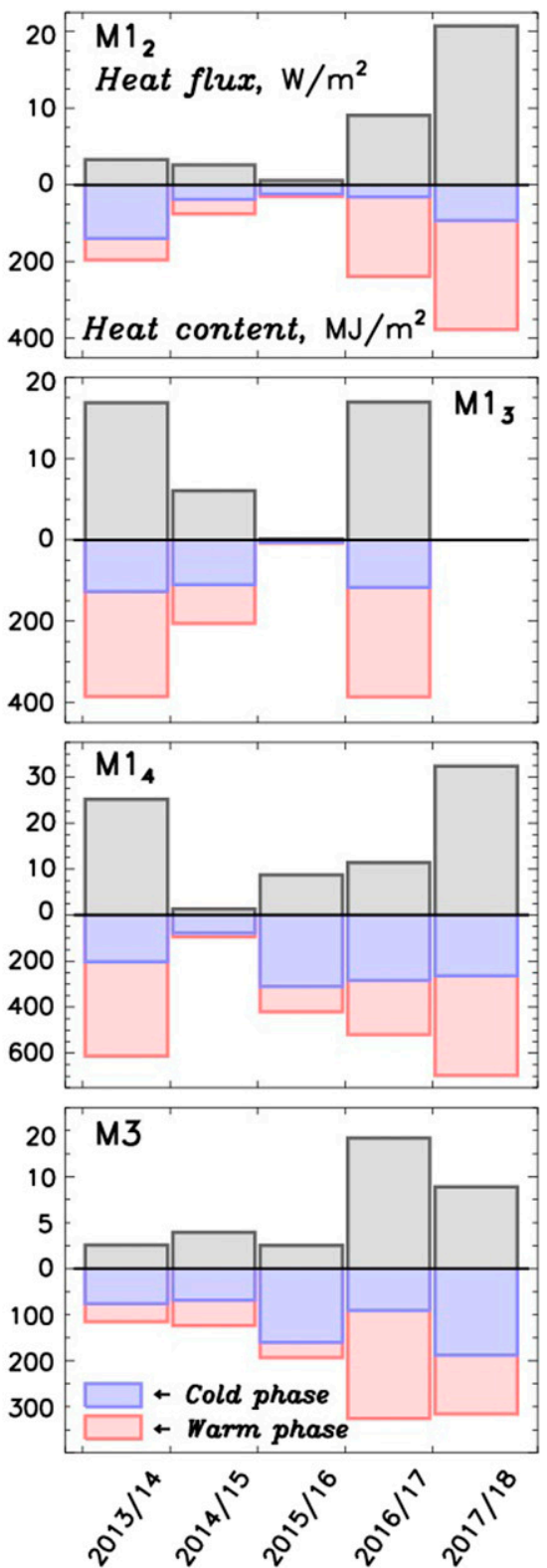

FIG. 4. The $65-140 \mathrm{~m}$ layer depth vs time of (left) water temperature and (center) annual component of heat content $Q$. Annual components are obtained via bandpass filtering using wavelet transformations. Horizontal black segments identify the depth of seasonal ventilation; dates identified by their ends are used to compute vertically integrated $Q$ shown in the lower parts of panels in the right column. (right) Vertically integrated $Q$ for the beginning (warm phase) and end (cold phase) of seasonal ventilation (shown in lower parts of the panels) and divergent heat fluxes $\delta F_{h}$ (upper parts) for four moorings.

(Fig. 5c) and a substantial increase in AW layer thickness (Fig. 6).

Cross-correlation analysis of time series of AW temperature measured at $250 \mathrm{~m}$ from 1997-2018 in Fram Strait, the entry point of AW into the Arctic, and from 2002-18 in the eastern EB (red time series in Fig. 5a) shows the strongest correlation, $R=0.67$, for a lag of 682 days (Fram Strait series leads; Fig. 5b). The fit between the two time series is better over the last 7-8 years than it is over the earlier period. The $\sim 2$-yr lag suggests that warm pulses of AW that entered the Arctic Ocean through Fram Strait are traveling toward the eastern 

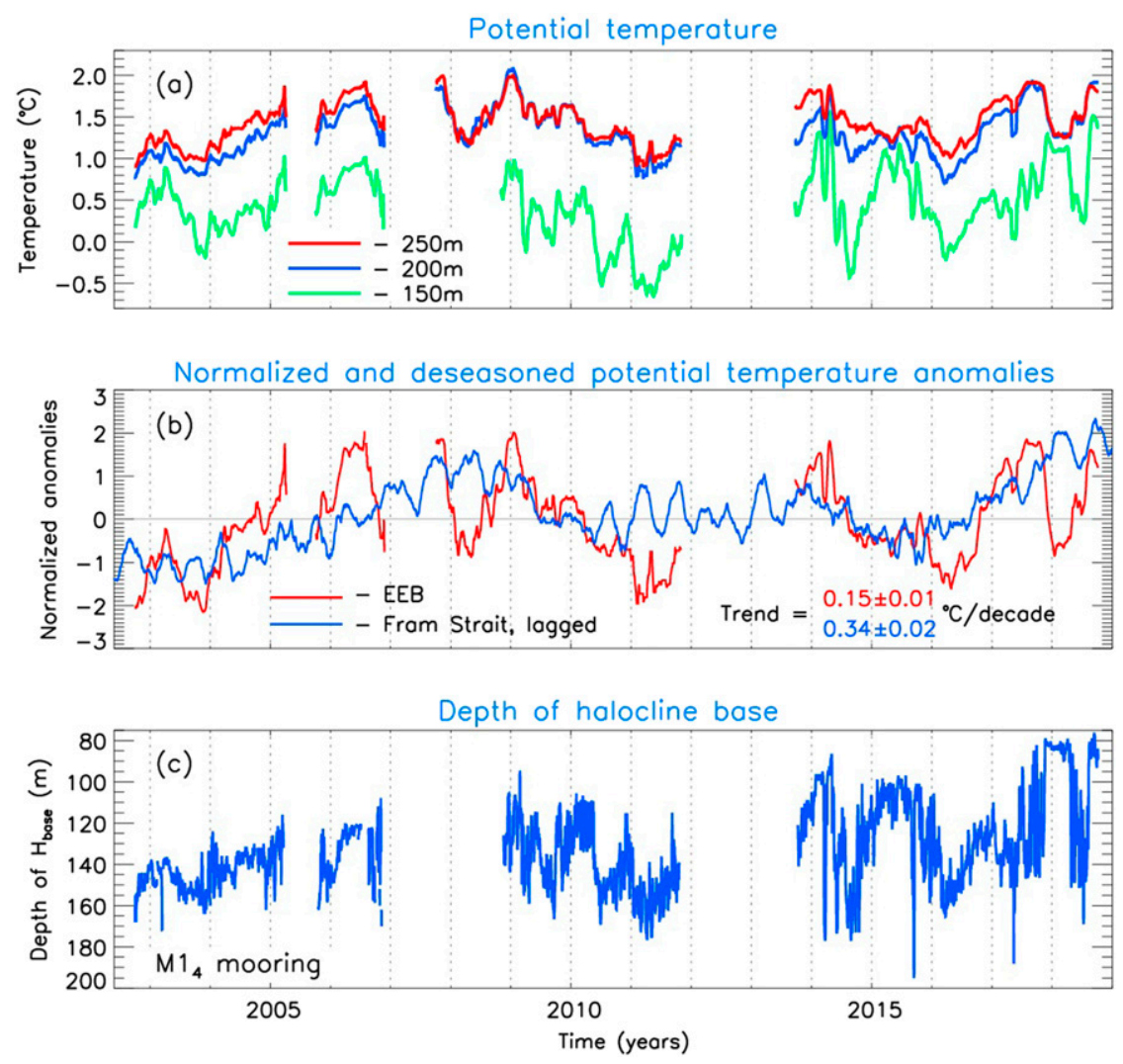

FIG. 5. Composite 2002-18 time series of (a) monthly mean potential water temperature $\theta$ and (c) daily depth of the lower halocline boundary $H_{\text {base }}$ defined by the $0^{\circ} \mathrm{C}$ isotherm at the $\mathrm{M} 1_{4}$ mooring location (for location, see Fig. 2). (b) Comparison of deseasonalized monthly mean time series of normalized $\theta$ anomalies from $250 \mathrm{~m}$ of the $\mathrm{M}_{4}$ mooring of the eastern $\mathrm{EB}$ (EEB) relative to F2-F3 moorings of Fram Strait lagged by 678 days (as obtained from correlation analysis); time series are normalized by their standard deviations.

EB at a speed 2-2.5 times faster than that estimated for a warm AW pulse that entered the eastern EB in 2004 (Polyakov et al. 2005). This implies that the rate of advection has increased over time. However, noisy data due to gaps in the EB record preclude meaningful statistical analysis using just the early part of the time series. Assuming that the lagged correlation between the two time series will persist in the near future, the latest part of the Fram Strait series (not shown) implies that the AW temperature in the eastern EB reached its peak in late 2018 (these data are not yet available) and will slowly decrease over the next 1-2 years.

Temperature and salinity profiles in the eastern EB from CTD during 2013-18 and MMP during 2003-18 recorded a decline of stratification $\left(N^{2}\right)$ over the 110 $140 \mathrm{~m}$ depth range of the halocline (Figs. 1c and 3a,b), which may be a result of both the shoaling of AW and weakening of halocline stratification. Polyakov et al. (2018) used available potential energy defined for the variable-depth halocline to show overall weakening stratification in the EB since the 1980s, with accelerated tendencies in the 2010s compared with the 2000s. However, there was substantial weakening of halocline stability from 2013 to 2015 (Polyakov et al. 2017), which continued in 2015-18, and which was also partially associated with shoaling of the AW (Fig. 6) found at $80 \mathrm{~m}$ depth, as inferred from the most recent observations in winter 2017/18 (Fig. 5c). This represents the shallowest depth the AW has been observed in the 15 years of mooring deployments. As these estimates used a linear interpolation of CTD time series made at 38 and $107 \mathrm{~m}$ at mooring $\mathrm{M1}_{4}$, we are not able to definitively conclude that the cold halocline layer was present (albeit very thin) during the winter of 2017/18. However, the record suggests the extreme thinning (or even absence) of the Arctic cold halocline layer for several months at this time (Figs. 5c and 6), implying that AW heat was exposed to winter convection associated with sea ice formation and brine rejection. 


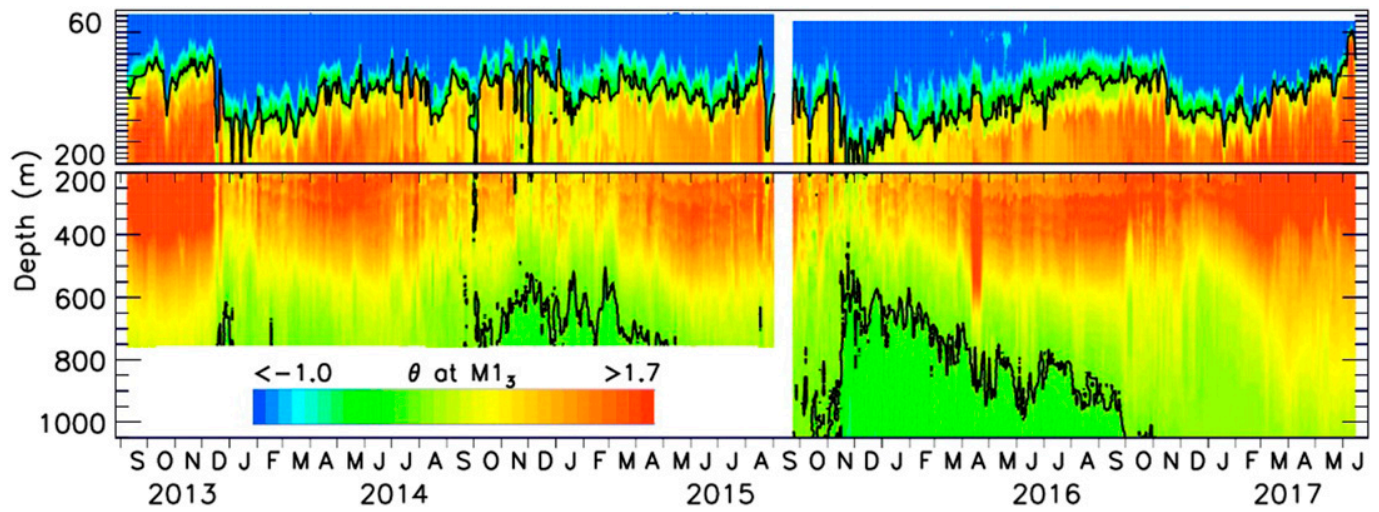

FIG. 6. Depth-time diagram of potential temperature $\theta\left({ }^{\circ} \mathrm{C}\right)$ from the $\mathrm{M} 1_{3}$ mooring. Black lines show the depth of the halocline base and lower Atlantic Water boundary, both defined by $0^{\circ} \mathrm{C}$ isotherms.

\section{b. Increased oceanic heat fluxes and ice loss in the eastern Eurasian Basin}

The weakening stratification, shoaling of the AW layer and increase of current shear in recent years (e.g., Polyakov et al. 2020b, manuscript submitted to Geophys. Res. Lett.) have altered the seasonal cycle of upward AW heat transport (Fig. 4). Estimated change in heat content $Q$ from the halocline $(65-140 \mathrm{~m})$ during winter, averaged at four moorings, is equivalent to mean divergent heat fluxes (see section 3 ) of $\delta F_{h}=12.0 \pm 5.5,3.5 \pm 2.2$, $3.0 \pm 1.9,12.9 \pm 1.7$, and $20.6 \pm 6.8 \mathrm{~W} \mathrm{~m}^{-2}$ for five winters from 2013/14 through 2017/18 (Figs. 4 and 7). For three of these winters $(2013 / 14,2016 / 17$, and 2017/ $18), \delta F_{h}$ greatly exceeded (from threefold to fivefold) the previous estimates derived from summer 2007/08 microstructure observations over the Laptev Sea slope (Lenn et al. 2009; Polyakov et al. 2019) and winter 2009/ 10 ITP-37 observations in the central Amundsen Basin (Polyakov et al. 2013). For the winters of 2014/15 and 2015/16, estimates of $\delta F_{h}$ were comparable to upward heat fluxes of about $3-4 \mathrm{~W} \mathrm{~m}^{-2}$ from $2007 / 08$. We attribute the decrease of $\delta F_{h}$ in 2015/16 (cf. Polyakov et al. 2017) to an anomalous freshening event in the upper ocean. This freshening is evident in data collected at mooring $\mathrm{M}_{3}$ (Fig. 8), which shows that strong upper $(<75 \mathrm{~m})$ ocean stratification (evidenced by high $N^{2}$ values) in 2016 precluded seasonal ventilation beyond the SML. Stronger stratification in winter 2015 compared with winters of 2014 and 2017 (Fig. 8d) limited seasonal ventilation to the upper $\sim 115 \mathrm{~m}$, thus not extending deeply enough to reach the main pool of AW heat (Fig. 8b). In consequence the heat flux is limited. The strongest heat flux is inferred for winter 2017/18 and is associated with the weakest stratification (Fig. 3), providing further evidence for the key role of stratification in mediating upper ocean ventilation.
The new estimates of seasonal ventilation of heat evaluated from the $\delta F_{h}$ for the winter seasons of 2016/17 and $2017 / 18$ are equivalent to $78 \pm 4$ and $93 \pm 29 \mathrm{~cm}$ reductions in ice growth, respectively, for the eastern EB (Fig. 7), given that one year of a heat flux of $1 \mathrm{~W} \mathrm{~m}^{-2}$ in isolation is equivalent to about $10 \mathrm{~cm}$ of sea ice loss. This represents a twofold increase in the sea ice loss rate
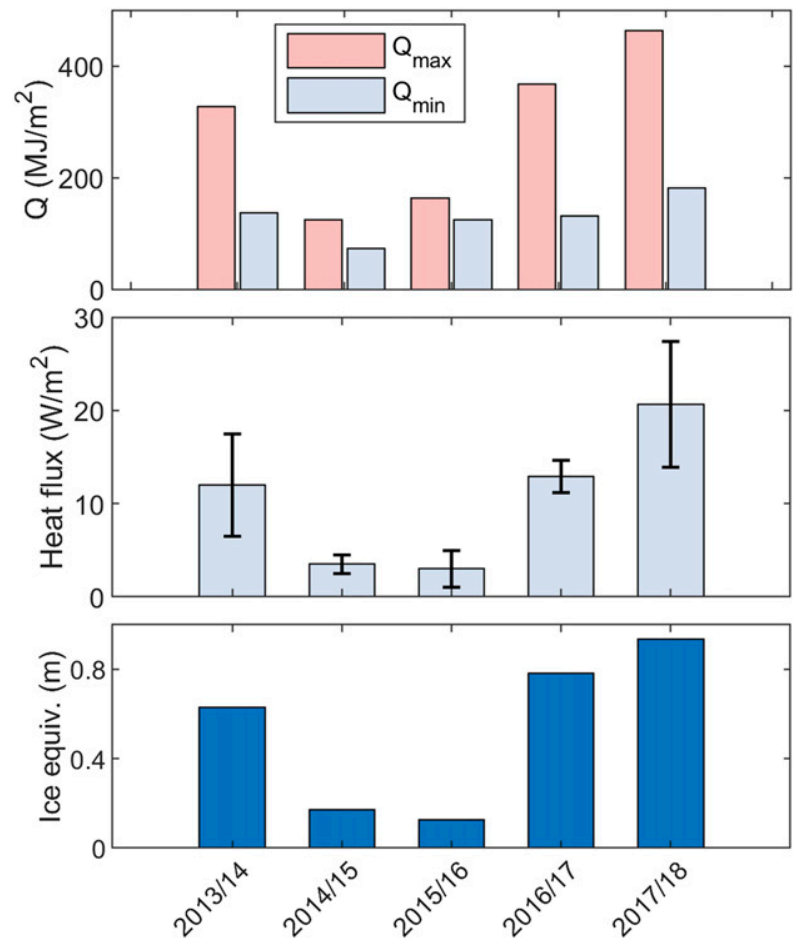

FIG. 7. (top) Vertically integrated $Q$ for the beginning (warm phase; red bars; $Q_{\max }$ ) and end (cold phase; blue bars; $Q_{\min }$ ) of seasonal ventilation of the eastern EB halocline $(110-140 \mathrm{~m})$, (middle) divergent heat fluxes $d F_{h}$ (blue bars for averages with \pm 1 standard error shown as black segments), and (bottom) equivalent sea ice thickness losses. Values are derived as averages over records at the $\mathrm{M} 3, \mathrm{M} 1_{2}, \mathrm{M}_{3}$, and $\mathrm{M} 1_{4}$ moorings. 

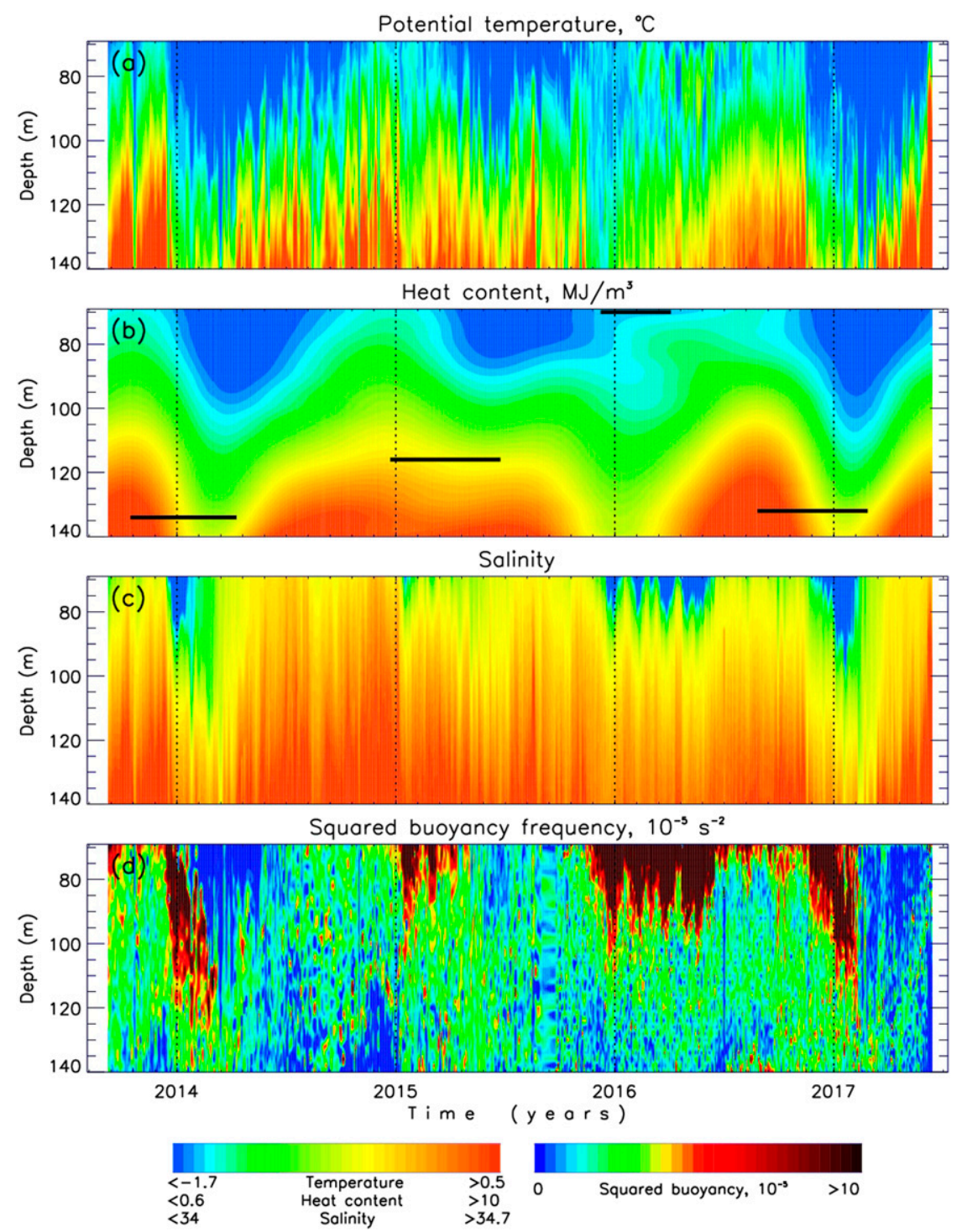

FIG. 8. (a) Potential temperature, (b) annual component of heat content $Q$ obtained by bandpass filtering of daily heat content using wavelet spectra; horizontal black segments identify the depth of seasonal ventilation, (c) salinity, and (d) squared buoyancy frequency for the $\mathrm{M} 1_{3}$ mooring.

compared to that estimated for $2013 / 14(54 \mathrm{~cm})$ and 2014/15 (40 cm) (Polyakov et al. 2017), and so partially explains intensified eastern EB sea ice loss in more recent years (Onarheim et al. 2018; Stroeve and Notz 2018).

Time series from the shallower moorings $\left(\mathrm{M}_{2}\right.$ and $\mathrm{M}_{3}$ ) show strong seasonal variations in the AW core temperature, which may be associated with seasonal displacement of the AW core relative to the slope (e.g., Baumann et al. 2018). However, the consistently low correlation between $Q$ and the AW core temperature records, for all mooring sites (Fig. 9), implies that crossslope shifts in AW temperature core are not a major driver of the seasonal variation in $Q$ in the halocline. The correlation between $Q$ and AW core temperature at the shallowest mooring $\left(\mathrm{M}_{2}\right)$ where currents are strongest is also weak $(R=0.29)$, indicating that advection does not provide a significant contribution to the seasonal variability of $Q$. This evidence is consistent with the results of Polyakov et al. (2017), who argued that the in-phase seasonal maxima and minima of wavelet transforms of $Q$ at all mooring sites suggests that the observed winter ventilation is driven by surface cooling and sea ice formation-and not by lateral advection. They reasoned that spatially varying water 

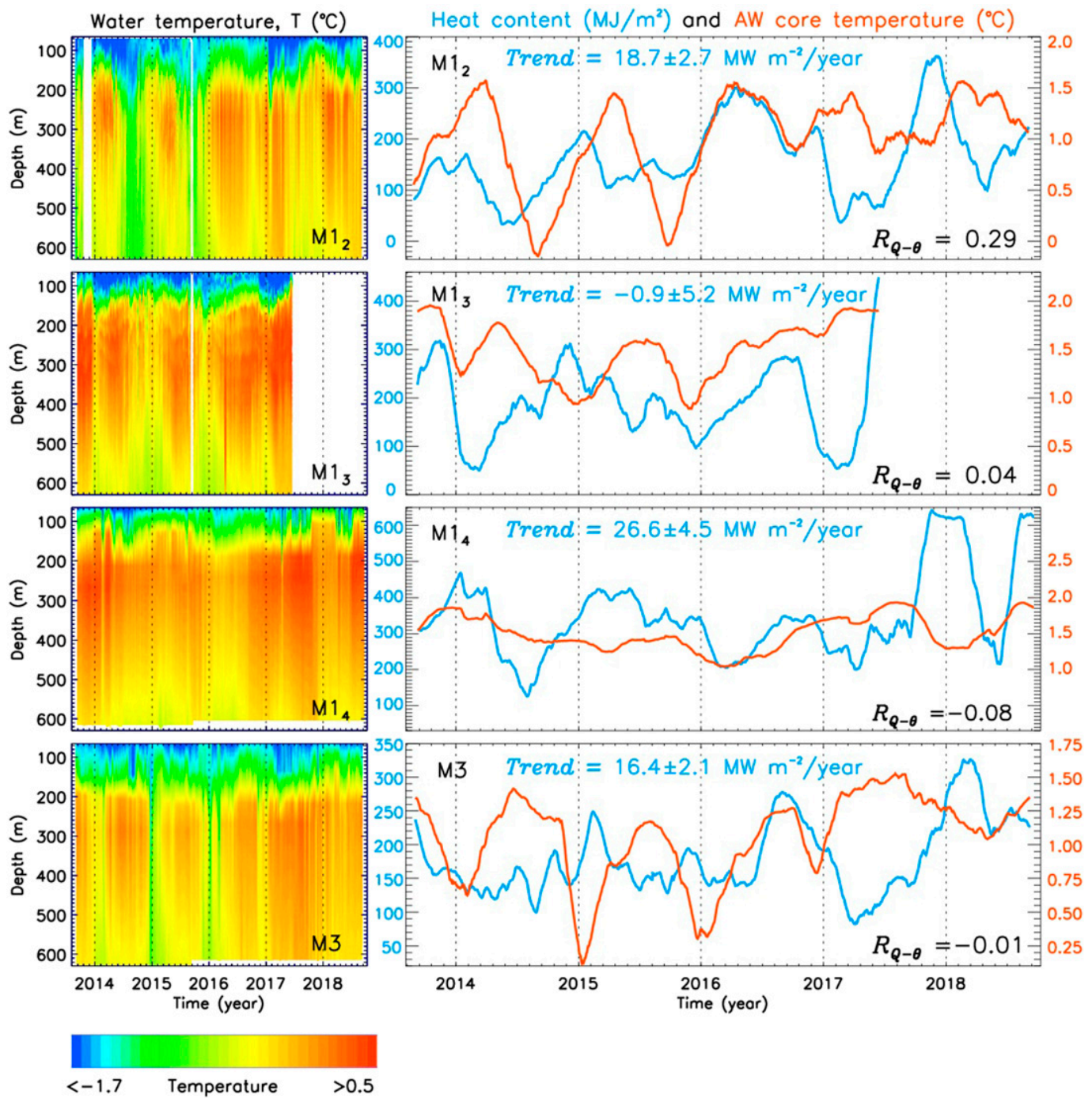

FIG. 9. (left) Depth vs time diagram of potential water temperature $\theta\left({ }^{\circ} \mathrm{C}\right)$ and (right) time series of monthly heat content $Q$ for the 65-140 m layer (blue) and AW core temperature (red) for four moorings. Low correlations between these time series $R_{Q-\theta}$ suggest that changes of $Q$ are not related to the seasonal shift of the AW core relative to the slope.

transports across the slope, ranging from $13 \mathrm{~cm} \mathrm{~s}^{-1}$ [measured over the upper continental slope $(250-700 \mathrm{~m})$ by moorings $\mathrm{M} 1_{1}$ and $\mathrm{M} 1_{2}$ ] to $1-2 \mathrm{~cm} \mathrm{~s}^{-1}$ (measured at $2700 \mathrm{~m}$ and deeper, at mooring locations $\mathrm{M} 1_{4}, \mathrm{M} 1_{5}$, and $\mathrm{M}_{6}$ ) make the in-phase pattern of the seasonal signal at all moorings impossible to explain using the advective mechanism. Furthermore, mooring $\mathrm{M}_{6}{ }_{6}$, which was farthest from the near-slope boundary current, in the ocean interior, yielded estimates for $F_{h}$ with magnitudes and phases consistent with estimates from the other moorings deployed on the eastern EB continental slope in 2013-15 (Polyakov et al. 2017).
The one-dimensional approach adopted here can be further validated by considering the magnitude of the lateral temperature gradient necessary to explain the estimated heat flux, if advection were to dominate. Taking our estimate of along-slope current speed of $2 \mathrm{~cm} \mathrm{~s}^{-1}$ implies that, to explain the estimated heat flux with lateral processes, the lateral temperature gradient $d T / d x$ would need to be about $4 \times 10^{-3}{ }^{\circ} \mathrm{C} \mathrm{km}^{-1}$, about 5 times larger than the observed value of about 0.75 $\times 10^{-4}{ }^{\circ} \mathrm{C} \mathrm{km}^{-1}$ between Fram Strait and the central Laptev Sea slope temperature $\left[1.8^{\circ} \mathrm{C}\right.$ of cooling (from $3^{\circ}$ to $1.2^{\circ} \mathrm{C}$ ) over $\sim 2400 \mathrm{~km}$ ]. Another potential contributor to the observed ventilation rates is lateral eddy 


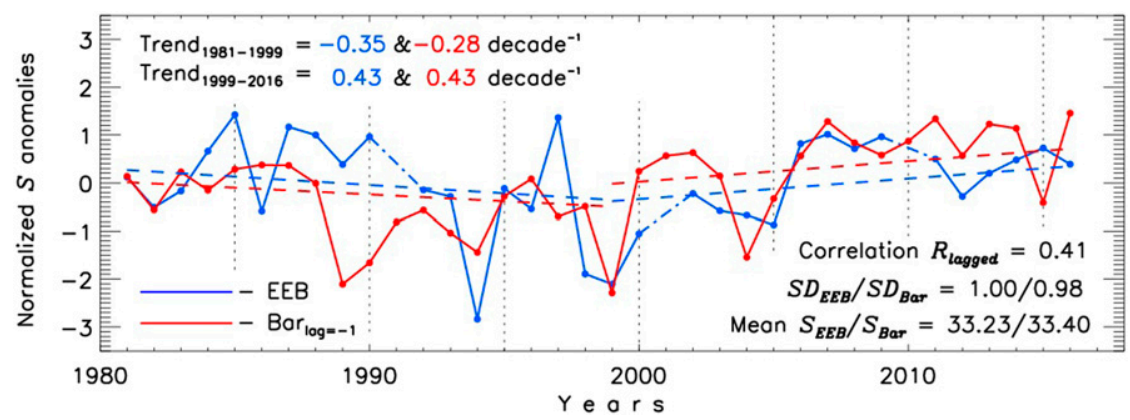

FIG. 10. Normalized [reduced to anomalies and divided by one standard deviation (SD)] annual time series of (blue) halocline salinity $S$ in the eastern EB [EEB; from Polyakov et al. (2018)] and (red) lagged by one year (as obtained from correlation analysis) upper ocean $S$ from the northern Barents Sea [from Lind et al. (2018)]. Dash-dotted lines are used to fill gaps (interpolated values are not used for statistical estimates). Means and SDs are indicated. Trends are shown by dashed lines; all trends are statistically significant at the $95 \%$ confidence according to the Student's $t$ test. The breakpoint in 1999 separates periods with opposite trends.

fluxes. Ventilation of halocline by eddies is, however, difficult to quantify using available data. Nevertheless, considering that the typical time of eddy passing across the mooring site is about a week with the average frequency about one eddy per month (Pnyushkov et al. 2018b), it is unlikely that eddies can significantly contribute to changes of the heat content at seasonal time scales. These considerations imply the uncertainty in the 1D flux calculation from lateral advection and diffusion is small.

\section{Discussion and conclusions}

Time series measurements from a 15-yr mooring record in the eastern EB of the Arctic Ocean demonstrate that the previously identified weakening of stratification over the halocline, which isolates intermediate depth AW from the sea surface, over the period 2003-15 (e.g., Polyakov et al. 2017, 2018), has continued at an increasing rate in more recent years (2015-18). In consequence, oceanic heat fluxes for the winters of 2016-18 are estimated to be greater than $10 \mathrm{~W} \mathrm{~m}^{-2}$. These fluxes are substantially larger than the previously reported winter estimates for the region for 2007/08 of 3-4 W m ${ }^{-2}$ (Lenn et al. 2009; Polyakov et al. 2019) and comparable to the estimates for the winters of 2013-15 (Polyakov et al. 2017), implying a significant enhancement of the role of oceanic heat in this region in recent years.

Moreover, the increased vertical heat fluxes have been accompanied by increased upper-ocean current speeds $|\mathbf{U}|$ and the magnitude of vertical shear in the horizontal velocities $\left|\mathbf{U}_{z}\right|$ over the period 2015-18 (Polyakov et al. 2020b, manuscript submitted to Geophys. Res. Lett.). Using mooring observations from 2003 to 2018, these authors showed that time-averaged values of $|\mathbf{U}|$ and $\left|\mathbf{U}_{z}\right|$ in the upper $60 \mathrm{~m}$ of the water column increased by about $20 \%$ and $40 \%$, respectively. In the lower halocline $(110-140 \mathrm{~m}),|\mathbf{U}|$ was generally larger after 2008, increasing on average from 2.5$3.5 \mathrm{~cm} \mathrm{~s}^{-1}$ in $2003-08$ to about $4-5 \mathrm{~cm} \mathrm{~s}^{-1}$ in $2009-18$ (Figs. 3c,d) although the change was not as strong in very recent years, 2016 and 2018, when compared to 2009-15. There is also a clear transition in $\left|\mathbf{U}_{z}\right|$, with significantly larger shears evident post-2010, and in particular in the summer of 2018 (Figs. 3c,d). However, Pnyushkov et al. (2018a) found no significant change in the mean alongslope water transport over the same period.

The combination of reduced stratification and increased shear implies a decrease of the gradient Richardson number ( $\mathrm{Ri}$ ) defined in section 3 (Figs. 3e,f), consistent with an increased turbulent heat flux, associated with vertical mixing by shear instabilities. Although the Ri estimates are based on $20 \mathrm{~m}$ vertical resolution measurements, they show a clear trend toward reduced dynamic stability, which may be interpreted as a tendency toward increased turbulent mixing in recent years, coincident with the increase in maximum halocline heat content (Fig. 4). This tendency is particularly strong in 2018 with amplified velocity shear in the relatively weakly stratified upper ocean (Fig. 3).

The increased shear and weakening of stratification as prerequisites for enhanced turbulent mixing are consistent with the recent transition in the upper ocean to conditions previously unique to the western Nansen Basin, a process called Atlantification (Polyakov et al. 2017). Our analyses confirm that, in part, the loss of stratification in the eastern EB halocline can be attributed to processes originating upstream. For example, the change in halocline salinity, the main contributor to water column stability in the eastern EB, is correlated with upper ocean salinity changes in the northern Barents Sea with a lag of approximately 2 years (Fig. 10) (Lind et al. 2018), revealing coherent interannual variability 

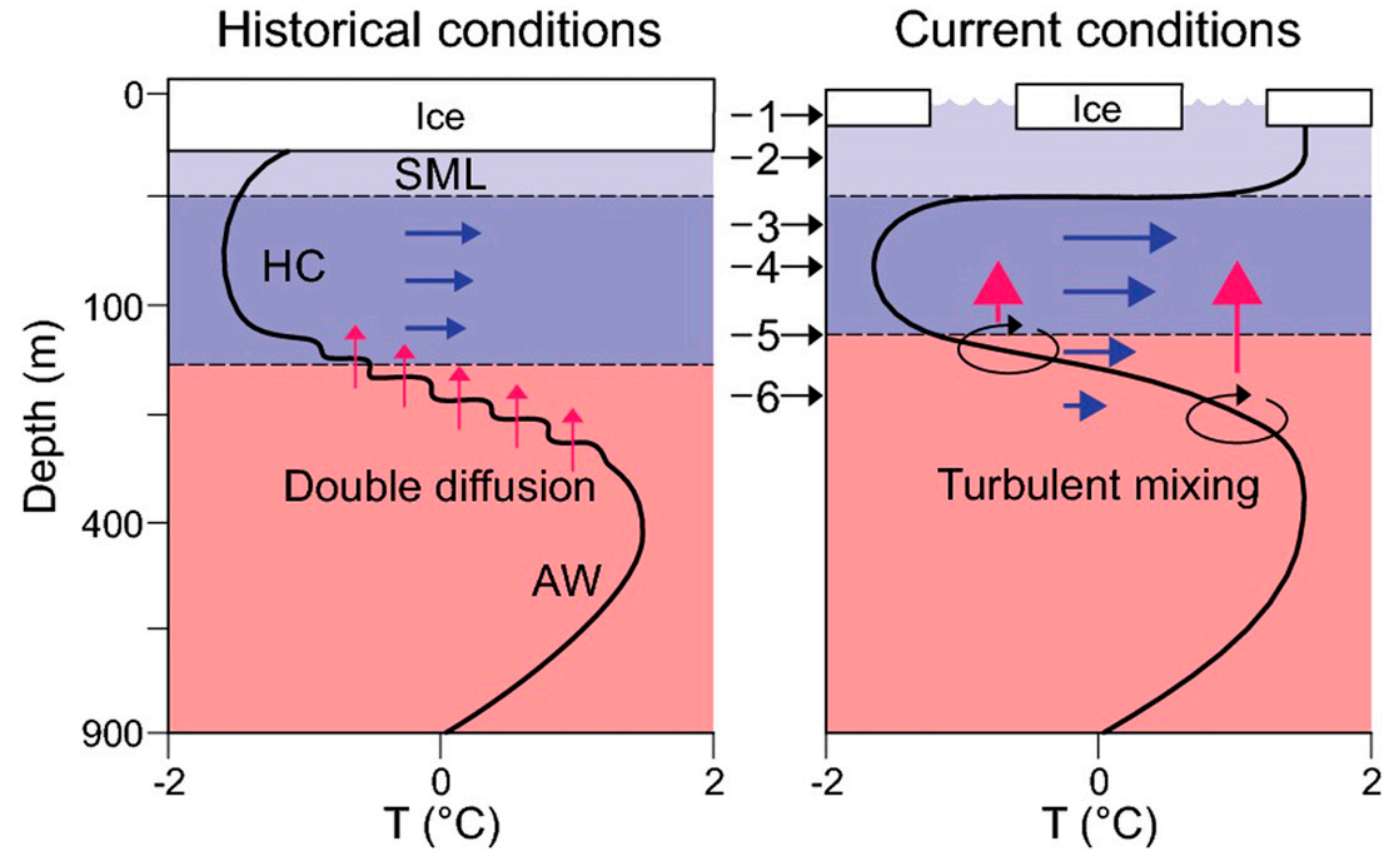

FIG. 11. Conceptual model of shift of the mixing regime in the eastern EB in recent years and associated suite of processes and state conditions including 1) thinner, more mobile ice, 2) warmer surface mixed layer (SML), 3) weakening/retreat of cold halocline (HC) layer, 4) increased AW vertical heat flux (red arrows) and horizontal currents and their vertical shear (blue arrows), 5) shoaling of upper AW boundary, and 6) replacement of DD by shear instabilities as the fundamental mechanism of vertical flux.

between the two regions. In the Barents Sea, these changes were found to be closely linked to declines in sea ice imports to the Barents Sea (Lind et al. 2018; Barton et al. 2018). The shift toward higher salinities in the eastern EB lags the changes in the northern Barents Sea by about 1 year (Fig. 10), implying an eastward lateral progression of Atlantification. Shelf-basin interactions may also be contributing to the observed warming (e.g., Timmermans et al. 2018).

Our observations point to the shift of this region of the eastern Arctic Ocean toward a new regime that is more typical of the continental slope regions of the western Nansen Basin where surface conditions are strongly influenced by oceanic heat imported from the Atlantic Ocean (Fig. 11). The flux of AW heat to the sea ice cover and the atmosphere has increased, during the winter season, from an average of $3-4 \mathrm{~W} \mathrm{~m}^{-2}$ in $2007-08$ to $>10 \mathrm{~W} \mathrm{~m}^{-2}$ in $2016-18$, equivalent to more than a twofold reduction of winter ice growth over the last decade.

The process described here represents a positive feedback, analogous to the ice-albedo feedback, since increased ocean heat flux to the sea surface reduces ice thickness and increases its mobility, increasing atmospheric momentum flux into the ocean and reducing the damping of surface-intensified baroclinic tides (Carr et al. 2019). We refer to this process as the ice-ocean- heat feedback. As with the ice-albedo feedback, the contribution of the ice-ocean-heat feedback to longterm sea ice trends depends on the seasonal variability of several factors that affect mixing rates including sea ice concentration and thickness, baroclinic tidal response to seasonally varying stratification, and wind stress impacts on sea ice and on AW shoaling. The transition in dominant mixing regime from double diffusion to shear-driven mixing also affects the relative magnitudes of buoyancy fluxes due to heat and salinity transports; the vertical diffusivities for heat and salt are the same in shear-driven turbulence, but are different for double diffusion (Kelley 1984). Coincident vertical nutrient fluxes, which support oceanic primary productivity, food web structure and carbon export from the atmosphere to the seabed (Bluhm et al. 2015; FalkPetersen et al. 2015), will also increase. Moreover, the nutricline has shoaled in recent years (Fig. 1d), relieving nutrient limitations, while declining sea ice cover relieves light limitations: both of these changes are influenced by Atlantification, suggesting regional-scale enhancement of biological productivity in the central Arctic Ocean.

As ice thins-through atmospheric forcing, changing ocean heat fluxes, and feedbacks - upper-ocean stratification is responding and a new Arctic state is emerging, which may not be easily reversed. For example, a large 

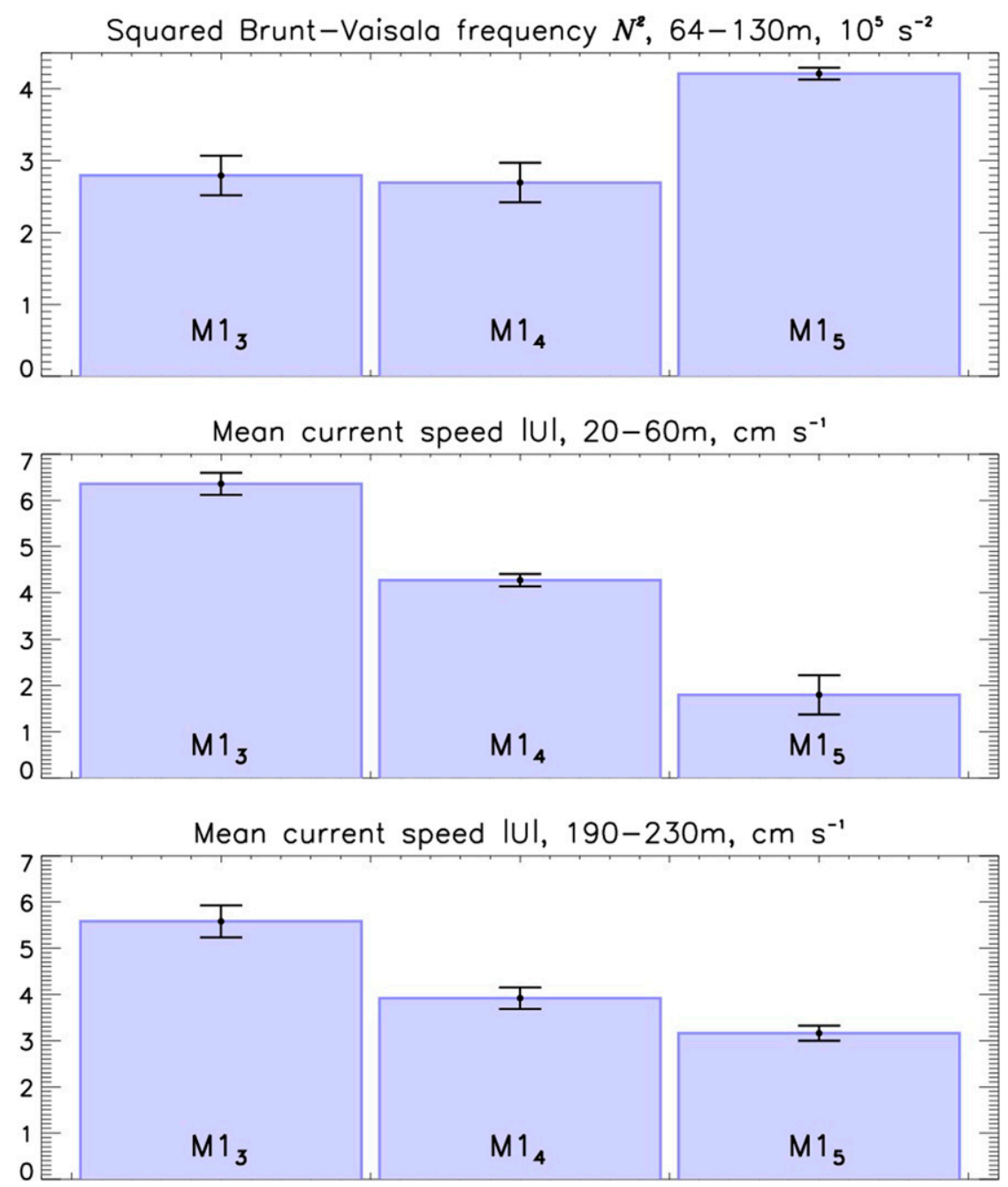

FIG. A1. The 2013-15 mean estimates of (top) squared Brunt-Väisälä frequency $N^{2}$, and current speed $|\mathbf{U}|$ for (middle) 20-60 and (bottom) 190-230 $\mathrm{m}$ depth ranges where the mooring records from $\mathrm{M}_{3}, \mathrm{M}_{4}$, and $\mathrm{M}_{5}$ overlap. Statistical significance of estimates for means is shown at the $95 \%$ confidence level.

anomaly in AW heat input coupled with shoaling may lead, through the ice/ocean-heat feedback, to an expanding and more permanent Atlantic-dominated state wherein the hydrographic structure of the halocline no longer provides sufficient insulation between the intermediate depth $\mathrm{AW}$ and the sea ice, even when the heat flux associated with the AW is relaxed. This potential for a permanent transition of the eastern Arctic to a new state emphasizes the pressing need for the incorporation of improved mixing schemes into Arctic climate models in order to better simulate the evolving halocline stratification and its impact on sea ice state.

Acknowledgments. The ship-based oceanographic observations in the eastern EB and Laptev Sea were conducted under the framework of the NABOS project with support from NSF (Grants AON-1203473 and AON1947162). Analyses presented in this paper are supported by NSF Grants 1708427 and 1708424 . The contributions from TPR and MAJ were supported by PEANUTS (NE/R01275X/1 and 03F0804A), part of the Changing Arctic Ocean programme, jointly funded by the UKRI Natural Environment Research Council (NERC) and the German Federal Ministry of Education and Research (BMBF). This paper is based in part on ideas discussed at an international workshop on pan-Arctic marine systems in Motovun Croatia, organized by $P$. Wassmann and supported by funding from Arctic SIZE (http://site.uit.no/arcticsize/). IF was supported by the Research Council of Norway through the AROMA project (294396). VI acknowledges funding from the Ministry of Science and Higher Education of the 

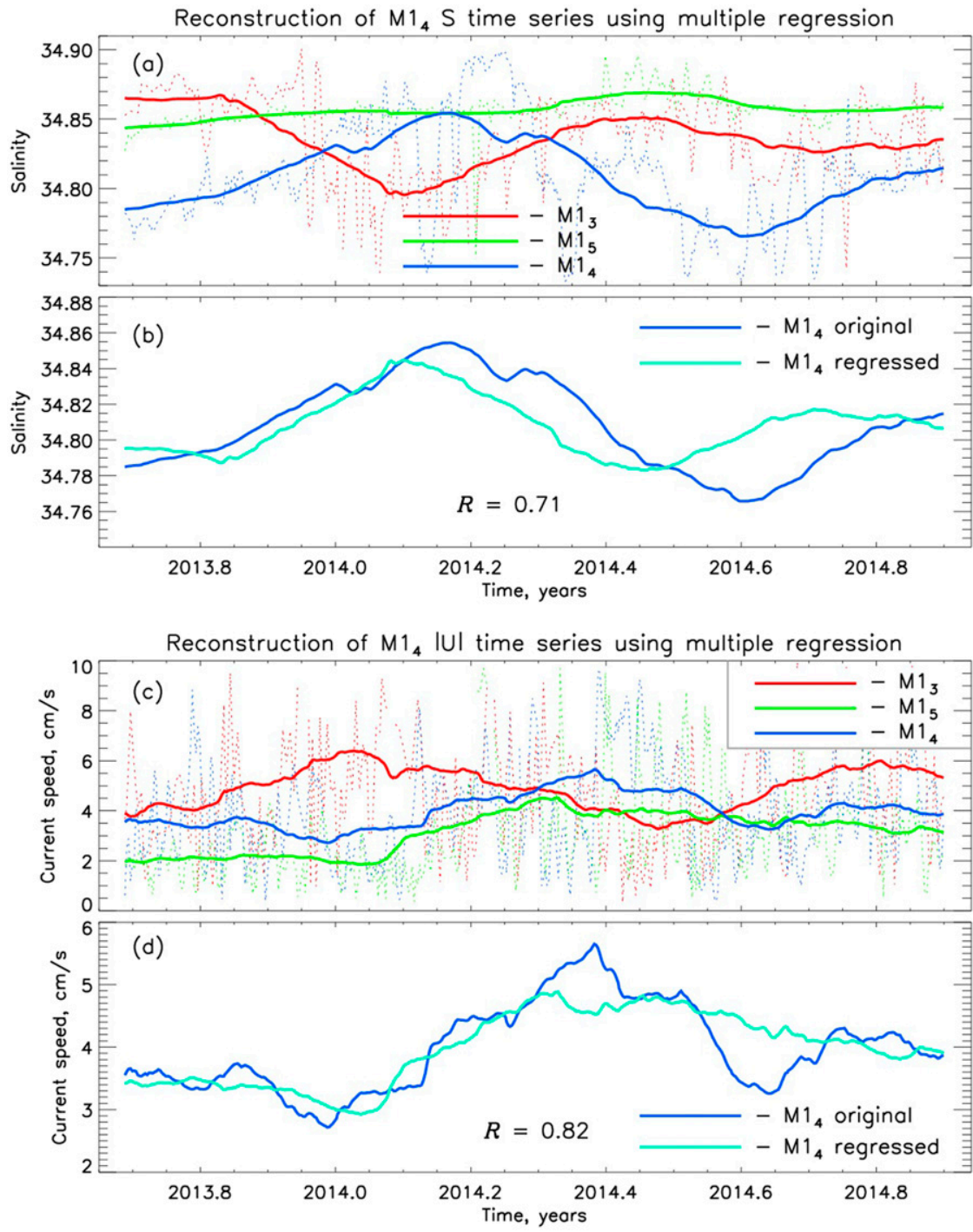

FIG. A2. Multiple regression reconstruction of (a),(b) salinity and (c),(d) current speed $|\mathbf{U}|$ at the $\mathrm{M}_{4}$ mooring site using data from the $\mathrm{M}_{3}$ and $\mathrm{M} 1_{5}$ moorings for $170-210 \mathrm{~m}$ depth range. Shown are the daily (dotted) and 3-month running mean smoothed time series of salinity in (a) and $|\mathbf{U}|$ in (c) from the $\mathrm{M}_{3}, \mathrm{M}_{4}$, and $\mathrm{M}_{5}$ moorings, and the original (blue) and reconstructed (red) time series of salinity in (b) and $|\mathbf{U}|$ in (d) from the $\mathrm{M}_{4}$ mooring. Relatively high correlations between the original and reconstructed time series attests of good quality of reconstruction.

Russian Federation (Project RFMEFI61619X0108). All mooring data used in this study are available at https://doi.org/10.18739/A2N37R and https://doi.org/ 10.18739/A2HT2GB80.

\section{APPENDIX}

\section{Building Long-Term Time Series}

Changes in the $110-140 \mathrm{~m}$ (halocline) layer at the $\mathrm{M} 1_{4}$ mooring site shown in Fig. 3 were documented using MMP records for 2003-07 and 2013-18, SBE37 records from M1g mooring in 2008-10, and ADCP records for 2008-10. This layer is the key part of the lower halocline water (Figs. 1a,b) and has sufficient data coverage for the task. All original mooring data were processed to make them comparable. We filtered MMP vertical profiles with a running-mean filter to reduce resolution to $4 \mathrm{~m}$, equivalent to the 2013-18 ADCP observations. We subsampled ADCP and SBE37 data in time to match coarser MMP temporal resolution. The vertical shear is calculated consistently using gradients over $20-\mathrm{m}$ vertical scale. Reconstruction of the record at the $\mathrm{M}_{4}$ mooring site 
in 2013-18 using MMP data from nearby moorings is described below.

There were no MMP measurements within the 110$140 \mathrm{~m}$ depth range at the $\mathrm{M}_{4}$ mooring in 2013-15 and 2015-18 (Table 1). Records for these years and depth range were reconstructed using weighted interpolated estimates from the neighboring $\mathrm{M}_{3}$ and $\mathrm{M} 1_{5}$ moorings.

This approach is justified by the observed monotonic cross-slope change of current speed from $\mathrm{M}_{3}, \mathrm{M}_{4}$, and $\mathrm{M} 1_{5}$ mooring records for the depth ranges where overlapping data are available for the three moorings (Fig. A1). Estimates of buoyancy frequency $N$ derived from temperature and salinity provided by these three moorings are statistically indistinguishable (Fig. A1).

Multiple regression is used to further validate the use of records from moorings $\mathrm{M}_{3}$ and $\mathrm{M}_{5}$ to reconstruct time series of temperature, salinity, and current speed at mooring $\mathrm{M}_{4}$ for 2013-18. The model of multiple regression is

$$
Y=\beta_{o}+\beta_{1} X_{1}+\beta_{2} X_{2}
$$

where $\beta_{1}=\left[\left(r_{Y X_{1}}-r_{Y X_{2}} r_{X_{1} X_{2}}\right) /\left(1-r_{X_{1} X_{2}}^{2}\right)\right]\left(\sigma_{Y} / \sigma_{X_{1}}\right), \beta_{2}=$ $\left[\left(r_{Y X_{2}}-r_{Y X_{1}} r_{X_{1} X_{2}}\right) /\left(1-r_{X_{1} X_{2}}^{2}\right)\right]\left(\sigma_{Y} / \sigma_{X_{2}}\right)$, and $\beta_{o}=\bar{Y}-$ $\beta_{1} \bar{X}_{1}+\beta_{2} \bar{X}_{2}$; the overbar denotes means, $\sigma$ denotes standard deviations, $r$ is used to denote cross-correlation coefficients, and the random error term is neglected. For independent parameters $X_{1}$ and $X_{2}$ the time series from $\mathrm{M} 1_{3}$ and $\mathrm{M} 1_{5}$ moorings are used, and the time series from $\mathrm{M}_{4}$ is used as the dependent variable $Y$. We neglected the high-frequency part of the records by applying low-pass 3-month running mean filtering to each time series used in the tests because in this study we mainly focus on longer-term (interannual) trends and changes. Evidence for the validity of this approach is provided in Fig. A2.

\section{REFERENCES}

Barton, B. I., Y.-D. Lenn, and C. Lique, 2018: Observed Atlantification of the Barents Sea causes the polar front to limit the expansion of winter sea ice. J. Phys. Oceanogr., 48, 1849-1866, https://doi.org/ 10.1175/JPO-D-18-0003.1.

Baumann, T. M., I. V. Polyakov, A. V. Pnyushkov, R. Rember, V. V. Ivanov, M. B. Alkire, I. Goszczko, and E. C. Carmack, 2018: On the seasonal cycles observed at the continental slope of the eastern Eurasian Basin of the Arctic Ocean. J. Phys. Oceanogr., 48, 1451-1470, https://doi.org/10.1175/JPO-D-17-0163.1.

Bluhm, B. A., K. N. Kosobokoba, and E. C. Carmack, 2015: A tale of two basins: An integrated physical and biological perspective of the deep Arctic Ocean. Prog. Oceanogr., 139, 89-121, https://doi.org/10.1016/j.pocean.2015.07.011.

Carmack, E., and Coauthors, 2015: Toward quantifying the increasing role of oceanic heat in sea ice loss in the new Arctic. Bull. Amer. Meteor. Soc., 96, 2079-2105, https://doi.org/ 10.1175/BAMS-D-13-00177.1.

Carr, M., and Coauthors, 2019: Laboratory experiments on internal solitary waves in ice-covered waters. Geophys.
Res. Lett., 46, 12 230-12 238, https://doi.org/10.1029/ 2019GL084710.

Falk-Petersen, S., V. Pavlov, J. Berge, F. Cottier, K. M. Kovacs, and C. Lydersen, 2015: At the rainbow's end: High productivity fueled by winter upwelling along an Arctic shelf. Polar Biol., 38, 5-11, https://doi.org/10.1007/s00300-014-1482-1.

Fer, I., 2009: Weak vertical diffusion allows maintenance of cold halocline in the central Arctic. Atmos. Oceanic Sci. Lett., 2 , 148-152, https://doi.org/10.1080/16742834.2009.11446789.

_, R. Skogseth, and F. Geyer, 2010: Internal waves and mixing in the marginal ice zone near the Yermak Plateau. J. Phys. Oceanogr., 40, 1613-1630, https://doi.org/10.1175/2010JPO4371.1.

Francis, J. A., S. J. Vavrus, and J. Cohen, 2017: Amplified Arctic warming and mid-latitude weather: New perspectives on emerging connections. Wiley Interdiscip. Rev.: Climate Change, 8, e474, https://doi.org/10.1002/WCC.474.

García-Serrano, J., C. Frankignoul, G. Gastineau, and A. de la Cámara, 2015: On the predictability of the winter EuroAtlantic climate: Lagged influence of autumn Arctic sea ice. J. Climate, 28, 5195-5216, https://doi.org/10.1175/JCLI-D-1400472.1.

Graham, R. M., and Coauthors, 2019: Winter storms accelerate the demise of sea ice in the Atlantic sector of the Arctic Ocean. Sci. Rep., 9, 9222, https://doi.org/10.1038/s41598-019-45574-5.

Kelley, D., 1984: Effective diffusivities within oceanic thermohaline staircases. J. Geophys. Res., 89, $10484-10488$, https:// doi.org/10.1029/JC089iC06p10484.

Kolstad, E., and J. Screen, 2019: Non-stationary relationship between autumn Arctic sea ice and the winter North Atlantic Oscillation. Geophys. Res. Lett., 46, 7583-7591, https://doi.org/ 10.1029/2019GL083059.

Kwok, R., 2018: Arctic sea ice thickness, volume, and multiyear ice coverage: Losses and coupled variability (1958-2018). Environ. Res. Lett., 13, 105005, https://doi.org/10.1088/ 1748-9326/aae3ec.

Lenn, Y.-D., and Coauthors, 2009: Vertical mixing at intermediate depths in the Arctic boundary current. Geophys. Res. Lett., 36 , L05601, https://doi.org/10.1029/2008GL036792.

Lind, S., R. B. Ingvaldsen, and T. Furevik, 2018: Arctic warming hotspot in the northern Barents Sea linked to declining sea-ice import. Nat. Climate Change, 8, 634-639, https://doi.org/ 10.1038/s41558-018-0205-y.

Manabe, S., and R. J. Stouffer, 1980: Sensitivity of a global climate model to an increase of $\mathrm{CO}_{2}$ concentration in the atmosphere. J. Geophys. Res., 85, 5529-5554, https://doi.org/10.1029/ JC085iC10p05529.

Mead Silvester, J., Y. D. Lenn, J. A. Polton, T. P. Rippeth, and M. M. Maqueda, 2014: Observations of a diapycnal shortcut to adiabatic upwelling of Antarctic Circumpolar Deep Water. Geophys. Res. Lett., 41, 7950-7956, https://doi.org/10.1002/ 2014GL061538.

Onarheim, I. H., T. Eldevik, L. H. Smedsrud, and J. C. Stroeve, 2018: Seasonal and regional manifestation of Arctic sea ice loss. J. Climate, 31, 4917-4932, https://doi.org/10.1175/JCLID-17-0427.1.

Padman, L., and T. M. Dillon, 1991: Turbulent mixing near the Yermak Plateau during the Coordinated Eastern Arctic Experiment. J. Geophys. Res., 4769-4782, https://doi.org/ 10.1029/90JC02260.

Perovich, D. K., J. A. Richter-Menge, K. F. Jones, and B. Light, 2008: Sunlight, water, and ice: Extreme Arctic sea ice melt during the summer of 2007. Geophys. Res. Lett., 35, L11501, https://doi.org/10.1029/2008GL034007. 
Pnyushkov, A. V., I. Polyakov, V. Ivanov, Ye. Aksenov, A. Coward, M. Janout, and B. Rabe, 2015: Structure and variability of the boundary current in the Eurasian Basin of the Arctic Ocean. Deep-Sea Res. I, 101, 80-97, https:// doi.org/10.1016/j.dsr.2015.03.001.

— , and Coauthors, 2018a: Heat, salt, and volume transports in the eastern Eurasian Basin of the Arctic Ocean from 2 years of mooring observations. Ocean Sci., 14, 1349-1371, https:// doi.org/10.5194/os-14-1349-2018.

—_, I. V. Polyakov, L. Padman, and A. T. Nguyen, 2018b: Structure and dynamics of mesoscale eddies over the Laptev Sea continental slope in the Arctic Ocean. Ocean Sci., 14, 1329-1347, https://doi.org/10.5194/os-14-1329-2018.

Polyakov, I. V., and Coauthors, 2005: One more step toward a warmer Arctic. Geophys. Res. Lett., 32, L17605, https:// doi.org/10.1029/2005GL023740.

_- and Coauthors, 2010: Arctic Ocean warming contributes to reduced polar ice cap. J. Phys. Oceanogr., 40, 2743-2756, https://doi.org/10.1175/2010JPO4339.1.

— , A. V. Pnyushkov, R. Rember, L. Padman, E. C. Carmack, and J. Jackson, 2013: Winter convection transports Atlantic Water heat to the surface layer in the eastern Arctic Ocean. J. Phys. Oceanogr., 43, 2142-2155, https://doi.org/10.1175/ JPO-D-12-0169.1.

_- and Coauthors, 2017: Greater role for Atlantic inflows on seaice loss in the Eurasian Basin of the Arctic Ocean. Science, 356, 285-291, https://doi.org/10.1126/science.aai8204.

—, A. V. Pnyushkov, and E. C. Carmack, 2018: Stability of the Arctic halocline: A new indicator of Arctic climate change. Environ. Res. Lett., 13, 125008, https://doi.org/10.1088/17489326/aaec1e.

, L. Padman, Y.-D. Lenn, A. V. Pnyushkov, R. Rember, and V. V. Ivanov, 2019: Eastern Arctic Ocean diapycnal heat fluxes through large double-diffusive steps. J. Phys. Oceanogr., 49, 227-246, https://doi.org/10.1175/JPO-D-180080.1.
— , and Coauthors, 2020a: Borealization of the Arctic Ocean in response to anomalous advection from sub-Arctic seas. Front. Mar. Sci., https://doi.org/10.3389/fmars.2020.00491, in press.

Provost, C., N. Sennechael, J. Miguet, P. Itkin, A. Rosel, Z. Koenig, N. Villacieros-Robineau, and M. A. Granskog, 2017: Observations of flooding and snow-ice formation in a thinner Arctic sea-ice regime during the N-ICE2015 campaign: Influence of basal ice melt and storms. J. Geophys. Res. Oceans, 122, 7115-7134, https:// doi.org/10.1002/2016JC012011.

Renner, A. H. H., A. Sundfjord, M. A. Janout, R. Ingvaldsen, A. Beszczynska-Möller, R. Pickart, and M. Peìrez-Hernaìndez, 2018: Variability and redistribution of heat in the Atlantic Water boundary current north of Svalbard. J. Geophys. Res. Oceans, 123, 6373-6391, https://doi.org/10.1029/ 2018JC013814.

Rippeth, T. P., B. J. Lincoln, Y.-D. Lenn, J. M. Green, A. Sundfjord, and S. Bacon, 2015: Tide-mediated warming of Arctic halocline by Atlantic heat fluxes over rough topography. Nat. Geosci., 8, 191-194, https://doi.org/10.1038/ ngeo2350.

Steele, M., and T. Boyd, 1998: Retreat of the cold halocline layer in the Arctic Ocean. J. Geophys. Res., 103, $10419-10435$, https:// doi.org/10.1029/98JC00580.

Stroeve, J., and D. Notz, 2018: Changing state of Arctic sea ice across all seasons. Environ. Res. Lett., 13, 103001, https:// doi.org/10.1088/1748-9326/aade56.

Timmermans, M.-L., J. Toole, and R. Krishfield, 2018: Warming of the interior Arctic Ocean linked to sea ice losses at the basin margins. Sci. Adv., 4, eaat6773, https://doi.org/10.1126/ SCIADV.AAT6773.

Toole, J. M., M. L. Timmermans, D. K. Perovich, R. A. Krishfield, A. Proshutinsky, and J. A. Richter-Menge, 2010: Influences of the ocean surface mixed layer and thermohaline stratification on Arctic sea ice in the central Canada Basin. J. Geophys. Res., 115, C10018, https://doi.org/10.1029/2009JC005660. 